\title{
Teatro de calle y mascarada de invierno. La tenazada: una recreación del rito de Los Carochos
}

Street theater and winter masquerade. La tenazada: a recreation of the rite of Los Carochos

\author{
M. Pilar Panero García \\ Universidad de Valladolid
}

\section{RESUMEN}

El día 1 de enero de cada año se celebra la mascarada Los Carochos en Riofrío de Aliste. Esta, con una acción ritual compleja y once personajes representando la mojiganga, es una de las más completas de las que se conservan en la provincia de Zamora. El 30 de enero de 2007 la compañía de teatro profesional Alkimia 130 dirigida por Mercedes Herrero Pérez (en colaboración con Fabularía Teatro) especializada en teatro de calle representan La tenazada, un homenaje al personaje del Carocho Grande después de una residencia de la compañía en la comunidad para conocer el rito. En la representación participó el pueblo y el resultado fue una performance en la que la frontera entre el rito original y espectáculo subjetivo está clara, pero con la que se genera una nueva ritualidad. Partimos del principio de Victor Turner de que el rito y el teatro son prácticas performativas del hombre que interpreta papeles continuamente porque es un homo performans. Veremos los elementos del rito vivo que se potenciaron en la representación que la compañía teatral y la comunidad hicieron; y analizaremos cómo la representación teatral a su vez trasciende el mero espectáculo cohesionando a los participantes y fijando la memoria local.

PALABRAS CLAVE: mascarada-Carnaval tradicional, pre-teatralización, rito, teatro de calle, Alkimia 130 


\begin{abstract}
On January 1 of each year is celebrated the masquerade Los Carochos in Riofrío de Aliste. This, with a complex ritual action and eleven characters representing the mojiganga, is one of the most complete of those preserved in the province of Zamora. On January 30, 2007 the professional theater company Alkimia 130 directed by Mercedes Herrero Pérez (in collaboration with Fabularía Teatro) specializing in street theater represent La tenazada, a tribute to the character of the Carocho Grande after a residency of the company in the community to know the rite. The people participated in the performance and the result was a performance in which the border between the original rite and subjective show is clear, but with which a new rituality is generated. We start from Victor Turner's principle that ritual and theater are performative practices of the man who plays roles continuously because he is a homo performans. We will see the elements of the living rite that were enhanced in the performance that the theatre company and the community made; and we will analyze how the theatrical performance in turn transcends the mere show by cohesing the participants and fixing the local memory.
\end{abstract}

KEY WORDS: masquerade-traditional carnival, pre-theatrical, ritual, street theater, Alkimia 130

El ideal del pueblo, a quien creo amar como un buen hijo a su madre, debe ser el ideal de la madre: el de morir, el de dejar de ser cuando haya prestado a todos sus hijos todas las condiciones de desenvolvimiento que les son necesarias. ¿Es triste? ¿Es dolorosa? ¿Es terrible esta ley? Dura, sed lex.

Don Antonio Machado y Álvarez

\title{
INTRODUCCIÓN
}

Mi interés por La tenazada fue fruto de una casualidad. En 2018 tuve la fortuna de coordinar científicamente la exposición "Máscaras en acción: Los Carochos" (Valladolid, 15 de noviembre-21 de diciembre), organizada por la Cátedra de Estudios sobre la Tradición (Universidad de Valladolid), el Ayuntamiento de 
Riofrío de Aliste y CEARCAL (Centro Regional de Artesanía de Castilla y León). ${ }^{1}$ Se expusieron máscaras, objetos e instrumentos musicales relacionados con el rito y una treintena de fotografías correspondientes a diecisiete autores de Inglaterra, Francia, Portugal y España. Parte destacada de esta exposición fue su componente pedagógico ya que colaboraron alumnos de la Escuela de Arte Superior de Conservación y Restauración de BC de Valladolid (Macho Blanco 2018a y 2018b) y la vieron niños y jóvenes de centros educativos (Dulzar 2019), ${ }^{2}$ aunque debido a las durísimas restricciones provocadas por la Covid-19 solo se desarrolló parcialmente.

Una de las preciosas fotografías hecha por José Luis Leal que seleccionamos para la muestra retrataba en un rito de varones a una mujer corriendo con el personaje la Gitana, esta última ya convertida en Filandorra. La mujer de la imagen invernal y colorida se mueve divertida porque la Filandorra la persigue para echarle encima cuanta ceniza pueda. Estas acciones bromistas son naturales en el ambiente lúdico de interacción entre los personajes protagonistas de la mascarada y los que asisten a ella. En la simbología de los antiguos ritos agrarios de contextos religiosos prerromanos se cumplen con este gesto dos acciones importantes, purificar, porque la ceniza se obtiene por la acción del fuego, y dispersar la fertilidad por contacto con algunos elementos del rito, especialmente sobre la tierra y las mujeres jóvenes. Hoy día, aunque he constatado que muchos participantes y público conocen el significado antiguo, esta mascarada y otras son un soporte para la identidad en un mundo globalizado. Supe que la mujer era Mercedes Herrero, directora teatral que había trabajado en dos performances sobre Los Carochos, a la que pude hacer una larga e interesante entrevista el 13 de septiembre de 2019 en Palencia. La hemos retomado con posterioridad, pues ella me ha resuelto muchas dudas en diferentes comunicaciones. Le agradezco aquí que tuviera la amabilidad de recibirme en su casa para hablar sin

${ }^{1}$ En 2019 la exposición, cuyo comisario fue el profesor José Luis Alonso Ponga, Director de la Cátedra de Estudios sobre la Tradición de la Universidad de Valladolid, se vio en Alcañices, 29 de abril-10 de mayo en el I.E.S. Aliste, y en Riofrío de Aliste, $10-25$ de agosto en su Ayuntamiento.

${ }^{2}$ Posteriormente (28/02/2020-18/05/2020) se programó montar la exposición en diez institutos de la provincia de Zamora con charlas y talleres siguiendo el modelo establecido en el I.E.S. de Alcañices. Proyecto "Patrimonio Cultural en Común" (0145_PATCOM_2_E). Programa Interreg España-Portugal 2014-2020, Junta de Castilla y León-Dirección General de Patrimonio Cultural (Consejería de Cultura y Turismo). Empresa Sercam SC. 
distracciones ni restricciones, la delicadeza de atenderme después tantas veces como he solicitado y, sobre todo, valoro que la narración de sus experiencias en Riofrío estuvo cargada de pasión y emoción.

Entre la casualidad arriba mencionada y este texto ha habido mucho trabajo de campo y estudio no solo de esta mascarada, sino de otras de la misma área que ya había iniciado en 2016 y se intensificó en 2019 participando en la elaboración de la documentación para una candidatura transnacional a la UNESCO como Patrimonio Mundial de la Humanidad. En ella se han incluido las mascaradas activas del distrito de Braganza y las provincias de Zamora y Salamanca: Mascaradas de inverno da Raia Ibérica no antigo território Zoela / Mascaradas de invierno de la Raya Ibérica en el antiguo territorio Zoela (Caramanzana et alii, 2019; Díaz Lorenzo et alii, 2020). La iniciativa ha sido favorecida por ZASNET, Agrupación Europea de Cooperación Territorial (AECT), que busca oportunidades para su territorio.

Desde 2018 he seguido especialmente las actividades del grupo encargado del mantenimiento de la mascarada Los Carochos interesándome, no tanto por una reconstrucción etnográfica de la mascarada en el pasado, que en este caso está muy bien hecha y publicada, sino por las herramientas que un grupo muy pequeño emplea hoy día para perpetuar su tradición con un entusiasmo fuera de lo común y canalizado por los jóvenes de la localidad y su Ayuntamiento. En este interés han sido especialmente sugerentes las conversaciones con los profesores António Tiza y José Luis Alonso Ponga. Con ambos coincido en que la máscara es parte radical de la cultura y en algunos lugares privilegiados, como es el caso, se mantienen estas joyas patrimoniales. En su adaptación a la modernidad va a soportar numerosos discursos que amparan el relato del pasado en relación con el presente. En esta polisemia del ritual profano situamos la performance de Alkimia 130 que construye, como la propia mascarada que imita (mímesis) y actualiza, un clima de sociabilidad igualitaria en la que, independientemente del atrezo, opera el capital humano y la mentalidad que el grupo tiene en cada momento de la historia. El objetivo de este trabajo es indagar precisamente en esa sociabilidad y las redes que la hacen posible más allá de la fecha señalada de Año Nuevo.

\section{CONTEXTO Y DESCRIPCIÓN DEL RITO}

Esta mascarada representada por once personajes es una de las más complejas que se conservan en la provincia de Zamora. Además, hay otro que es colectivo, el 
pueblo entero que también participa y, desde tiempos recientes, se suman los visitantes y curiosos que acuden a la celebración. El rito - los personajes y sus acciones - ha sido descrito ya de forma exhaustiva por Juan Francisco Blanco González (2004) y de forma somera, pero clara por diversos autores (Blanco González 2009; Rodríguez Pascual 2009: 122-143; Calvo Brioso 2012: 487-498; Panero García 2020: 34-49). El audiovisual del cineasta Arturo Dueñas (2019) explica la mascarada en relación a las conservadas en Abejera y Sarracín de Aliste, ambas localidades pertenecen al municipio de Riofrío de Aliste y se celebran también el día de Año Nuevo. La fecha de celebración está dentro del "Ciclo de los Doce Días", es decir, en el tiempo que transcurre entre Navidad y Epifanía. Durante este periodo se representan muchas mascaradas del Carnaval tradicional, pues como ha señalado Caro Baroja en su emblemático estudio histórico-antropológico publicado en 1965 (2006:155-160), la Navidad pertenece al ciclo de Carnaval. El único origen rastreable está en las fiestas romanas Kalendae Ianuariae en honor al dios Jano (Ianus), que en la mitología romana representa los comienzos, las transiciones y los finales.

Los Carochos no se pueden entender sin considerar un contexto geográfico y cultural amplio. Es una de las diecinueve mascaradas que se conservan actualmente en la provincia de Zamora que están relacionadas con las que se celebraban en la de Salamanca, que ha recuperado recientemente una, y las treinta y una del distrito de Bragança en Trás-os-Montes (Díaz Lorenzo et alii, 2020). Estas mascaradas de La Raya, como se conoce la frontera políticoadministrativa, que no es cultural ni social puesto que los habitantes de ambos lados mantienen una identidad cultural y relaciones de vecindad sin percibir la división como tal, son restos de ritos arcaicos que se ejecutan en el s. XXI con una nueva significación. Cualquier taxonomía topográfica es ajena a la dinámica propia de la cultura tradicional antes de su folklorización, aunque ahora gracias a las acciones difusionistas puede ser asimilada y adaptada por diversos grupos que la incorporan a su legado cultural. En cualquier caso, estas mascaradas son fiestas agrarias antiguas que se celebran en un contexto económico-social nuevo en el que la división de los tiempos de ocio y trabajo son los modernos, pero en los que la máscara ha encontrado su sitio.

Las mascaradas zamoranas admiten clasificaciones diferentes si consideramos el número de personajes — protagonistas y acompañantes—, la acción o en el protagonismo del elemento más representativo que es la máscara - demoniaca, zoomorfa o mixta - (Rodríguez Pascual 2009: 25-26; Calvo Brioso 2012: 34-37). Frente a los zangarrones, mascaradas vacunas o carnavales, Los Carochos son una 
obisparra en la que la pre-teatralización la ejecutan cuatro grupos de personajes - los diablos o carochos, los guapos, El del Lino y los ciegos-interpretados por varones jóvenes, puesto que el colectivo de los mozos que se encargaba antiguamente de la función no existe (Tabla 1).

\begin{tabular}{|c|c|c|}
\hline \multicolumn{3}{|c|}{ Mascaradas zamoranas del Carnaval tradicional } \\
\hline \multirow[t]{3}{*}{$\begin{array}{l}\text { Enmascarados } \\
\text { fustigadores }\end{array}$} & El Zangarrón de Sanzoles & $\begin{array}{ll}25 \text { y } 26 & \text { de } \\
\text { diciembre } & \end{array}$ \\
\hline & El Tafarrón de Pozuelo de Tábara & 26 de diciembre \\
\hline & El Zangarrón de Montamarta & 1 y 6 de enero \\
\hline \multirow{8}{*}{$\begin{array}{ll}\text { Obisparras: varios } \\
\text { cuadros escénicos } \\
\text { en los que el } \\
\text { protagonismo } \\
\text { recae en un } \\
\text { enmascarado }\end{array}$} & $\begin{array}{l}\text { El Pajarico y el Caballico de Villarino } \\
\text { tras la Sierra }\end{array}$ & 26 de diciembre \\
\hline & La Filandorra de Ferreras de Arriba & 26 de diciembre \\
\hline & La Obisparra de Pobladura de Aliste & $\begin{array}{l}\text { Desplazada al } 15 \\
\text { de agosto } \\
\text { (antiguamente el } \\
26 \text { de diciembre) }\end{array}$ \\
\hline & La Bisparra de Triufé & $\begin{array}{l}31 \text { de diciembre o } \\
1 \text { de enero }\end{array}$ \\
\hline & Los Diablos de Sarracín de Aliste & 1 de enero \\
\hline & Los Carochos de Riofrío de Aliste & 1 de enero \\
\hline & Los Cencerrones de Abejera & 1 de enero \\
\hline & $\begin{array}{l}\text { El Atenazador de San Vicente de la } \\
\text { Cabeza }\end{array}$ & $\begin{array}{l}\text { Desplazada al 11de } \\
\text { agosto } \\
\text { (antiguamente el } \\
29 \text { de junio) }\end{array}$ \\
\hline
\end{tabular}




\begin{tabular}{|c|c|c|}
\hline \multirow{7}{*}{$\begin{array}{lr}\text { Vacas y } & \text { toros: } \\
\text { máscaras vacunas o } \\
\text { taúricas, } \\
\text { pueden } & \text { que } \\
\text { como mixtas } \\
\text { talanqueiras } \\
\text { humana y las } \\
\text { animal) o simples }\end{array}$} & La Bisparra de Vigo de Sanabria & 26 de diciembre \\
\hline & $\begin{array}{l}\text { La Talanqueira de San Martín de } \\
\text { Castañeda }\end{array}$ & 5 de enero \\
\hline & Vaca Bayona de Carbellino & Carnaval \\
\hline & Vaca Bayona de Almeida & $\begin{array}{l}\text { Carnaval / } \\
\text { entre 10-14 } \\
\text { agosto }\end{array}$ \\
\hline & Vaca Antrueja de Pereruela & Carnaval \\
\hline & $\begin{array}{l}\text { Toro de Carnaval de Morales de } \\
\text { Valverde }\end{array}$ & Carnaval \\
\hline & $\begin{array}{l}\text { La Vaquilla o "Cencerreros" de } \\
\text { Palacios del Pan }\end{array}$ & Carnaval \\
\hline Carnaval & $\begin{array}{l}\text { Los Carnavales de Villanueva del } \\
\text { Valrojo }\end{array}$ & Carnaval \\
\hline
\end{tabular}

Tabla 1. Elaboración de la autora siguiendo la clasificación de F. Rodríguez Pascual (2009).

Nos referimos a ella como pre-teatralización o mojiganga entendida esta última como una forma no dramática de diversión popular carnavalesca en la que participaban personajes grotescos que llevaban vejigas hinchadas que se llamaban "bojigangas", que con los años sube al escenario estilizando el Carnaval (Grillo Torres 2004: 184-185). Antiguamente el personaje del Gitano llevaba vejigas de cerdo hinchadas para golpear al público (Blanco González 2004: 144-145). Aunque esta pre-teatralización del día 1 no es el rito completo de Los Carochos, pues tenía otros momentos importantes antes de ese día - los preparativos y los entrenamientos- y después - El Entruejo con el que los niños remedaban a los grandes-, sí es la parte fundamental por lo que nos podemos referir a ella como tal. En los últimos años los entrenamientos son más laxos y el Carnaval chiquito se ha incorporado a la fecha de la mascarada, por lo que vemos a los niños emulando a los grandes con sus pequeñas máscaras y tenazas (ver Figura 1). 
Los diablos (carochos) son dos, el Diablo Grande y el Diablo Chiquito, que son dos de los tres personajes que se cubren el rostro. En ellos predomina el color negro que se emplea para toda la indumentaria - pantalones, chaquetas, leguis y botas-y en manos y las caras tiznadas con unas corchas quemadas en la lumbre. La cabeza del Grande se cubre con una máscara (carocha) de corcho negro logrado con pez derretido, con agujeros a la altura de los ojos y boca, dientes de hojalata blancos y nariz de hojalata roja, cuernos de corcho pintados de rojo en la parte superior, perilla de cerdas de yegua y hacia la espalda le cae una piel de oveja ribranca (negra con el rabo blanco). La cabeza del Chiquito está tocada con una gran melena de pelos de caballo o yegua que se remata con orejas de liebre, que hace las veces de máscara peluda que cubre el rostro durante la función. Ambos hacen mucho ruido al moverse pues el Grande lleva cencerros anudados en la espalda y el chiquito cencerras sobre un mullido de zarzas. El atributo del Grande son unas tenazas rojas articuladas y el del compañero dos corchas con las que tiznar las caras de la gente, y ambos llevan mochila (ver Figura 2).

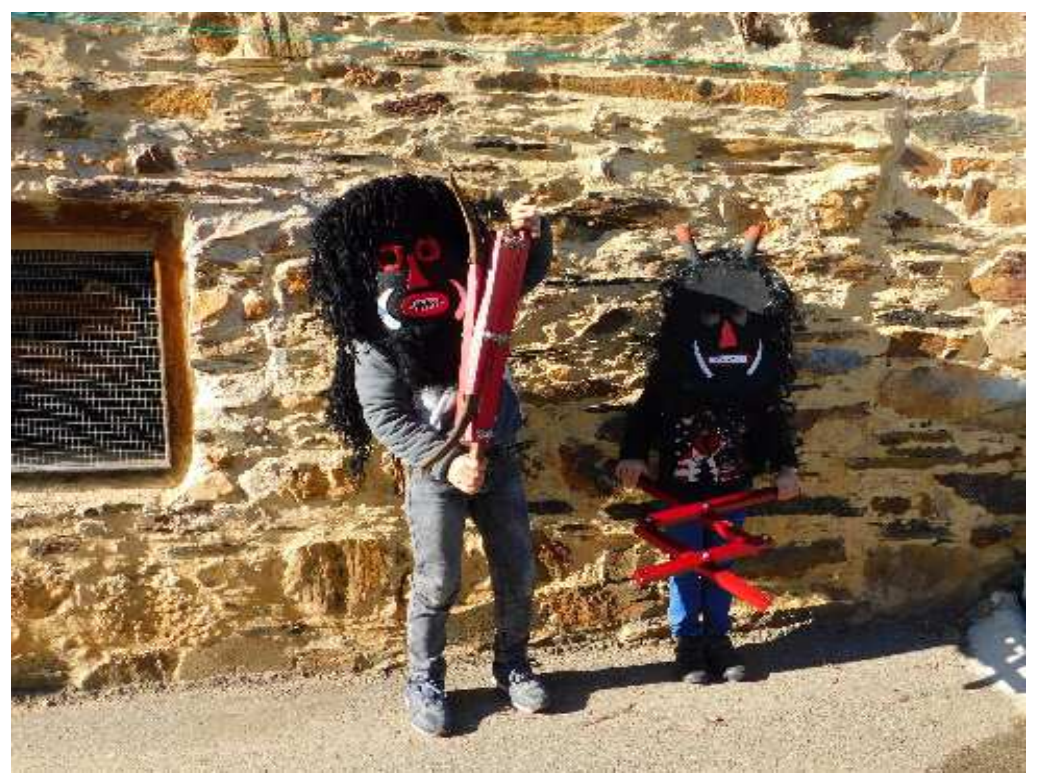

Figura 1. Los niños, también las niñas, emulan a los personajes de la mascarada durante su celebración. Fotografía de M. ․ P. Panero. 


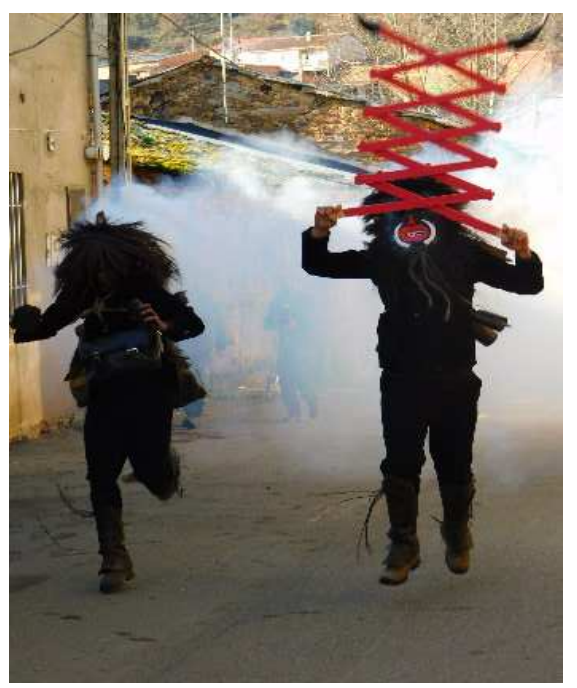

Figura 2. Los carochos recorren las calles el día 1 de enero exhibiendo sus atributos, las corchas y las tenazas. Fotografía de M.. P. Panero.

El grupo de los guapos lo forman el Galán (porta una vara y toca las castañuelas) y la Madama con el Niño (un muñeco al que arrulla continuamente), son padres que se disponen a bautizar a su hijo. Los acompañan El del Cerrón, suerte de padrino del Niño, y El del Tamboril (toca este instrumento). Los guapos no interactúan con los demás personajes, pero están presentes encarnando al pueblo por el que pasean vistiendo la indumentaria tradicional alistana.

El del Lino actúa solo y camina cojeando. Viste como un pobre de solemnidad con chaqueta corta, calzones, una chola, esquila en la cintura y es el tercer enmascarado pues se cubre con máscara de piel de libre que le cubre la cabeza. Su nombre se debe a que lleva lino. Tizna las caras del público con una corcha quemada y acosa irreverentemente a las mujeres con su cayada.

La familia de los filandorros o gitanos lo forman el Molacillo, el Ciego, el Gitano (Filandorro) y la Gitana (Filandorra), aunque más que una familia en sentido estricto es "una comunidad de intereses" (Blanco González 2004: 108). El Molacillo representa a un militar, viste de blanco como su rostro, también pintado de blanco, con faja roja, calza unas botas y en su cabeza lleva un tocado, especie de morrión rematado con plumas y flores, con mensajes de crítica social que se renuevan cada año. Lleva dos mochilas cruzadas donde guarda la caracola 
y unas conchas y los aguinaldos. Porta una pica roja rematada en un aguijón y una tralla.

El Ciego viste pobre y burdamente con ropas raídas como la capa confeccionada en arpillera sobre la que se cosen cruces hechas con gamones - planta de la familia de las liliáceas - con caperuza rematada en tiras largas de papel que caen sobre la espalda. No va enmascarado, pero unas gafas tosquísimas y grandes de corcho hacen el efecto de que lo fuera. Su atributo es una especie de zanfona de corcho, llamada corcho porque es una vieja colmena a la que se le ha puesto una manivela que mueve varias esquilas que al girar suenan; y también lleva un cuerno de vaca que cuelga de su cuello.

El Gitano viste pobremente con chaqueta y pantalones remendados estampados y de vistosos colores. Su tocado es un sombrero de paja agujereado y calza abarcas o botas con agujeros. Como atributos lleva un reloj de madera, una bota de vino, una pelota - látigo de la que pende una cuerda que en un extremo tiene una raíz de brezo forrada de trapos viejos que hacen de pelota compacta-, una navaja o unas tijeras de esquilar, una mochila, una albarda o alforjas de fibra vegetal que son el aparejo de un burro al que monta. Antiguamente llevaba unas vejigas de cerdo hinchadas que utilizaba para golpear al público (Blanco González 2004: 144-145).

La Gitana hace su primera aparición vestida de gitana con prendas remendadas una falda larga de volantes y chambra colorida-, pañuelo merino en la cabeza, llamativo chal de lana y joyas - pendientes, pulseras y un enorme collar de buyacas, los frutos del roble- - Sus atributos son un huso, la rueca llamada naspa y una cesta de mimbre llena de fruslerías para interactuar con el público como vendedora.

El Gitano y la Gitana son los personajes que cambian de traje en un momento dado, ella antes de la primera pelea de su grupo con los diablos y él después de esa pelea, pero un poco más tarde. Cuando la Gitana se cambia es la Filandorra que viste un traje largo hecho con tiras de papel. Se la reconoce a pesar del cambio de indumentaria por el collar. Porta un caldero con ceniza que arroja al público, siendo este gesto el más representativo. El Gitano también cambia sus ropas por un traje largo de tiras de papel convirtiéndose en Filandorro y se le reconoce por la pelota (ver Figura 3). 


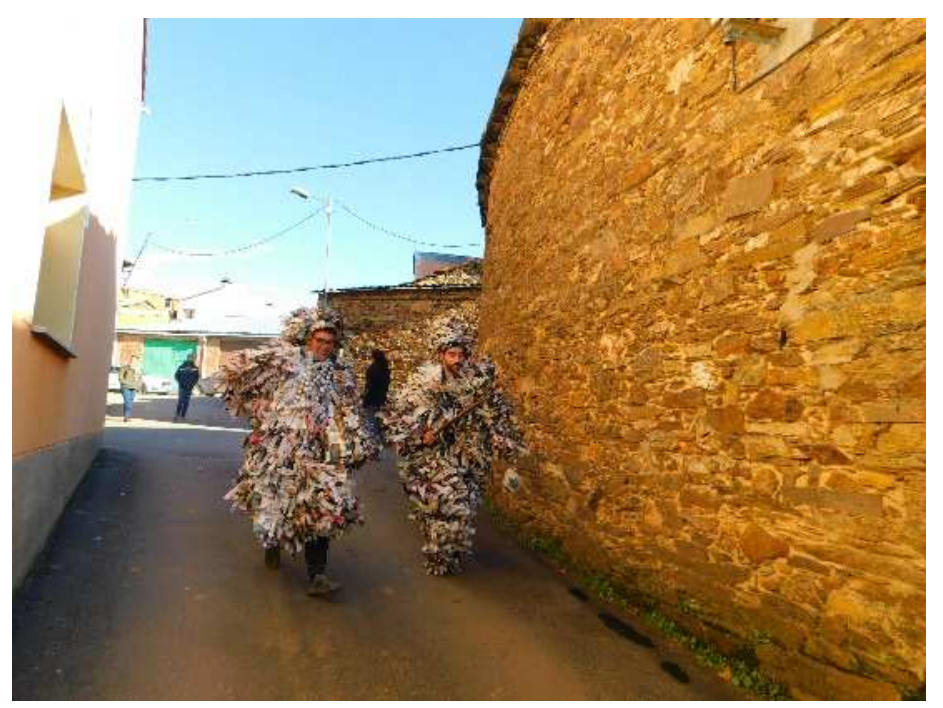

Figura 3. El Filandorro (antes Gitano) y la Filandorra (antes Gitana) se reconocen por sus atributos, la pelota para fustigar y el collar respectivamente. Ella también lleva un martillo para llamar a las puertas. Fotografía de M. P. Panero.

La acción brevemente resumida es la siguiente. Salen todos los personajes de un mismo local en la calle principal. Los primeros son los carochos envueltos en el humo que sale de un bote, como el que se utiliza en los teatros, que lleva el Grande en su espalda. Ambos hacen ruido con los cencerros, el Grande mueve las tenazas articuladas y el Chiquito da gritos sobrecogedores. Después sale el grupo de los guapos, el Galán toca las castañuelas y El del Tamboril su instrumento y El del Cerrón y la Madama van a su lado. Detrás de ellos renqueante y solo va El del Lino. Finalmente salen los filandorros con tres burros, dos tiran del carro que dirige El Molacillo y en el que va de pie la Gitana y en la parte trasera el Ciego, llamado Ciego de Atrás. Cierra la comitiva el Gitano con el tercer burro haciendo cabriolas, cayéndose y provocando la risa del público. En un momento este grupo es detenido por alguien que hace las veces de autoridad y se fiscaliza su presencia en el pueblo. Los filandorros dan todo tipo de explicaciones en un diálogo jocoso.

Los grupos continúan un recorrido establecido hasta que se llega a la casa del cura donde un sacerdote de verdad simula el bautizo del Niño de la Madama. Después del sacramento los grupos van en el orden establecido hacia el "Sagrao", la plaza donde está la iglesia. Allí se vuelca el carro de los filandorros que, hasta ese momento, han interactuado con el público vendiendo las bagatelas de la Gitana y hasta el burro del Gitano. El Ciego resulta accidentado y el Molacillo y el Gitano 
provocan las risas intentando reanimarlo. Como sus remedios no dan resultados y el Ciego parece moribundo buscan la ayuda de un médico, primero, y cuando esta falla de un cura entre los asistentes. Ambos son de pega y se suceden durante un largo rato diversas vejaciones al moribundo que provocan la risa. En un momento dado, mientras se representa esta escena, la Filandorra se cambia y aparece con un caldero lleno de ceniza que esparce entre los presentes desprevenidos. Mientras tanto El del Lino se acerca a las mujeres, les levanta faldas o abrigos, las agarra con la cayada... (ver Figura 4).

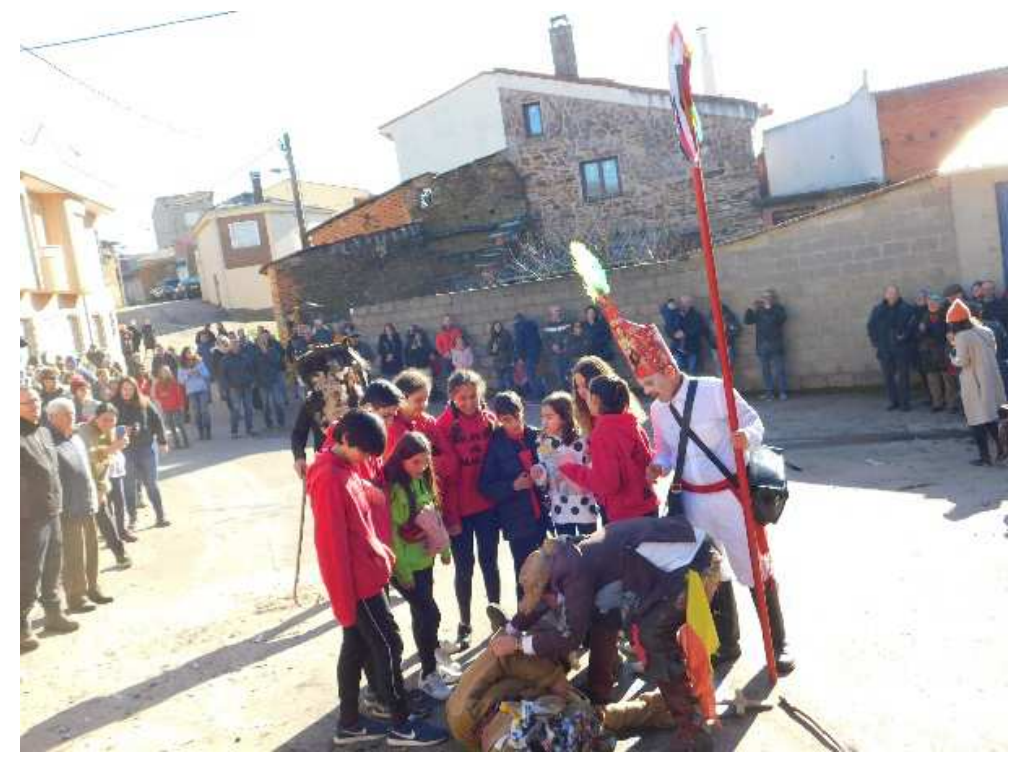

Figura 4. El Gitano y el Molacillo atienden al Ciego que está moribundo con los ayudantes. Detrás enmascarado está El del Lino haciendo de las suyas con su cayada. Fotografía de M. ․ P. Panero.

De repente, hay un ataque de los carochos, se produce la primera pelea y desaparece el Ciego de Atrás. El Molacillo y el Gitano que han ahuyentado al Diablo Grande y al Diablo Chiquito lo buscan por los sitios más insospechados con las señas incorrectas que el público les da. El Molacillo toca la caracola para llamar al Ciego y este responde con el sonido de su cuerno, circunstancia que le indica al Molacillo donde está y va a buscarlo ya que ellos son dos personajes hermanos, de hecho, al Molacillo también se le conoce como Ciego de Adelante y al Ciego como apuntamos Ciego de Atrás. Este aparece vivo y su compañero lo trae amarrado con una soga. En ese momento el Ciego toca la zanfona, el 
Molacillo toca las conchas y canta coplas picantes, de crítica social... sobre hechos relevantes que han sucedido y algunas del acervo popular mientras el Gitano y la Filandorra bailan haciendo cabriolas, cayéndose... Cuando termina este baile los filandorros inician el recorrido que los otros grupos ya han hecho por el pueblo para pedir el aguinaldo - por eso en todos los grupos alguien lleva mochila- y felicitar las fiestas a todos los vecinos que hospitalariamente los reciben con comida y bebida despidiéndose con la fórmula "Que de hoy en un año" (ver Figura 5).

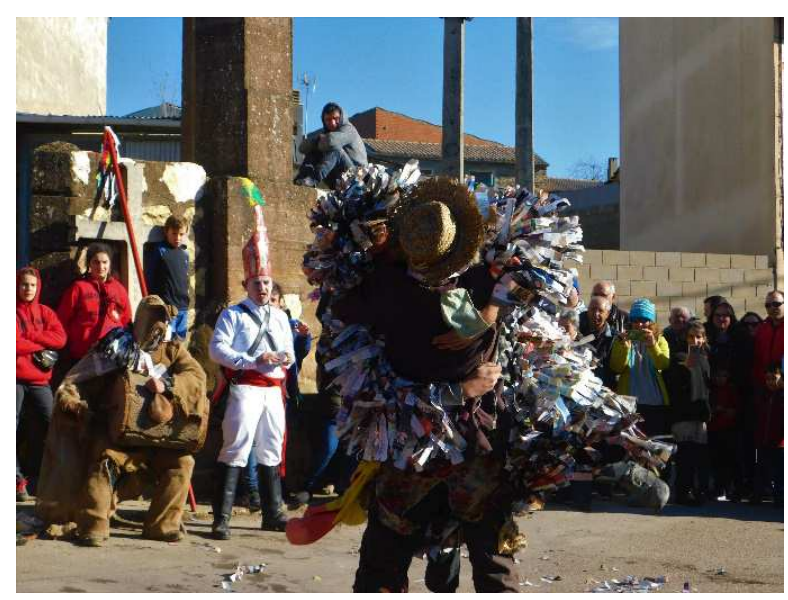

Figura 5. El Ciego toca el corcho, el Molacillo las conchas y canta, el Gitano y la Filandorra bailan locamente en el "Sagrao". Fotografía de M.. P. Panero.

Cada grupo hace su recorrido, pero hay momentos en los que se suceden más peleas, entre diablos y filandorros. En la ronda de cuestación-felicitación el Gitano ya lleva el traje de papel. Se continúa en esta dinámica hasta que al final de la mañana los carochos cruzan el río Frío y continúan con la ronda por el pueblo, recibiendo agasajo en las casas, hasta que, más tarde, se juntan en la plaza del "Sagrao" donde bailan todos al son de la gaita y el tamboril con el público y los carochos dan de comer chorizo a los presentes. Se producen un nuevo ataque al Ciego y los otros filandorros los defienden del Carocho Grande y del Carocho Chiquito que son expulsados hasta el próximo año (ver Figura 6). 


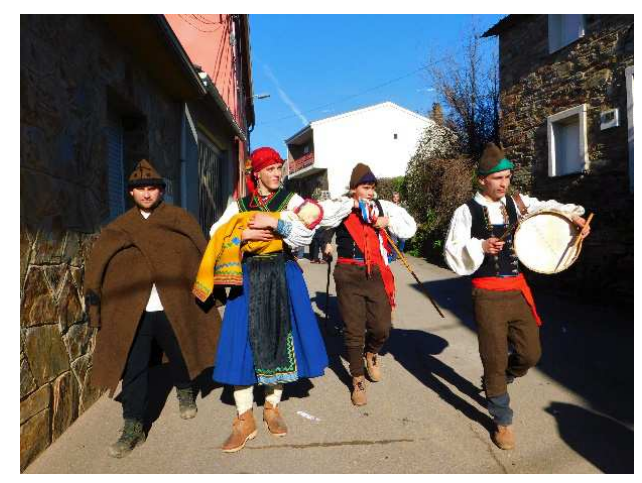

Figura 6. El del Cerrón, la Madama con el Niño, el Guapo y El del Tambor son los guapos. Recorren las calles pidiendo el aguinaldo y deseando parabienes. Fotografía de M.․ P. Panero.

\section{EL COMPORTAMIENTO RESTAURADO}

Richard Schechner, director teatral y profesor del Departamento de Estudios de Performance de la Universidad de Nueva York, mantuvo un fecundo intercambio intelectual sobre la performance con el antropólogo Victor Turner en los años 70 del pasado siglo que cristalizó en el libro Between Theatre and Anthropology publicado en 1985. Antes, Turner había publicado From Ritual to Theater (1982) y, después, Schechner prologó The Anthropology of Performance (1986) de Turner. $^{3}$ Parafraseamos a Richard Schechner (1988; 2011) que llama "restauración del comportamiento" o "restauración de la conducta", twicebehaved behavior, a un comportamiento vivo que existe independientemente de quien lo realice, aunque la "verdad" o la "fuente" de dicho comportamiento se haya perdido y que se da, entre otras situaciones, en un ritual tradicional como es el caso de Los Carochos. La mascarada es un acto performativo pues transmite la memoria social y la identidad de la comunidad. Esta participa de forma reiterada y normativa con unos actores sociales que ensayan: "I find it useful, because I like to think of ritual essentially as performance, enactment, not primarily as rules or rubrics. The rules «frame» the ritual process, but the ritual process transcends its frame" (Turner 1982: 79). Entendemos performance en este sentido turneriano de acto, proceso, transmisión y también intervención en el mundo de los que la

\footnotetext{
3 Acerca de la estela que han dejado estas iniciativas inspiradoras para otros especialistas como Eugenio Barba que con Nicola Savarese desarrolla la Antropología teatral (1988) hasta fechas recientes puede verse Prieto Stambaugh y Toriz Proenza (2015: 24-26).
} 
ejecutan, es decir, como representación que revela el carácter más profundo y genuino de la cultura de un grupo, donde la normas que marca la tradición dirigen la conducta, pero estas se pueden rebasar incorporando otras actuaciones en el ámbito tradicional que aporten nuevos significados y nuevos símbolos. ${ }^{4} \mathrm{La}$ performance es un acto simbólico que da las claves reales del sentir y pensar del grupo. A través de la tradición esta asume los cambios socioculturales con la ilusión de prolongación con respecto a los que los precedieron:

\begin{abstract}
As society complexifies, as the division of labor produces more and more specialized and professionalized modalities of sociocultural action, so do the modes of assigning meaning to social dramas multiply — but the drama remains to the last simple and ineradicable, a fact of everyone's social experience, and a significant node in the developmental cycle of all groups that aspire to continuance (Turner 1982: 78).
\end{abstract}

La compañía Alkimia 130 (1995-2011) se ha caracterizado por la indagación en el rito a través de la dramaturgia del teatro de calle y por una sensibilidad especial hacia el ámbito rural. Cuando Mercedes Herrero, Directora Artística, es invitada por Riofrío para crear una performance dedicada a la mascarada en torno a la figura más emblemática del rito, el diablo principal o Carocho Grande en 2007 la respuesta fue positiva. ${ }^{5}$ No nos referimos al género concreto performance art, sino a la práctica teatral que establece lo que Dubatti ha nombrado como "convivio" entre espectadores y performers (cit. Abraham, 2008: 84). La teatralización se decide hacer dos días antes de la mascarada porque la comunidad está expectante ante la celebración de su rito, pero hay tiempo suficiente para que el espectáculo o teatralización como representación subjetiva y artificial no lo invada. Además, coincidiendo con las vacaciones de Navidad

\footnotetext{
${ }^{4}$ No existe consenso sobre la traducción de performance en español y portugués, aunque lo performativo tiene arraigo, proponiendo teatralidad y espectáculo o representación y acción. Según Diana Tylor (2011: 25-28) limitan su alcance optando por la definición de Antonio Prieto Stambaugh: “«esponja mutante» que absorbe ideas y metodologías de varias disciplinas para aproximarse a nuevas formas de conceptualizar el mundo".

${ }^{5}$ El desarrollo fue gratificante para ambas partes y en 2009 se lleva a cabo una segunda experiencia en torno al personaje de la Gitana o Filandorra con el título Hilando filando. Se hará una residencia, pero en base a un curso para crear un espectáculo contemporáneo a través de un rito y en el que la performace será la práctica.
} 
muchos de los más de setenta participantes pueden ensayar. Previamente, la compañía había realizado una residencia pura en Riofrío para investigar la mascarada desde tres soportes: principalmente a través de las historias de vida de la comunidad transmitidas oralmente; con la literatura etnográfica sobre Los Carochos publicada en ese momento (Blanco González 2004; Calvo Brioso 2007); y con la cultura audiovisual pues desde hace años las mascaradas son objeto de interés de numerosos fotógrafos y de la prensa. ${ }^{6} \mathrm{El}$ tema se centró especialmente en el enmascarado principal, personaje carismático que metonímicamente da nombre a la celebración, y en su emblema, las largas tenazas articuladas de color rojo que utiliza en sus luchas.

La labor de restauración del comportamiento se lleva a cabo en los ensayos y en la transmisión de la conducta del maestro, que en este caso son los conocedores y transmisores de la mascarada, al aprendiz, los integrantes de Alkimia 130.7 Es ineludible comprender lo que sucede durante la preparación con los ensayos, talleres e investigación para relacionar la performance teatral o estética con el ritual (Schechner 2011: 36). En una residencia pura se investiga acerca de la realidad y vivencias de un grupo concreto, aunque integrado por personas anónimas, con una perspectiva humanista y un compromiso que necesariamente tiene un código deontológico como explica Mercedes Herrero Pérez: "Entrevisto, observo, estudio, fotografío. Miro y escucho de cerca. Pido permiso para contarlo, desde el respeto y no la exhibición, y lo muestro al mundo desde una flecha lanzada de verdad y preguntas que comprometan al otro en la escucha y no le inviten al juicio fácil o a la opinión superficial" (Delgado Pascual 2017: 5).

La directora ha trabajado en el ámbito rural con el objetivo de poner en valor su relato y sus valores a través de la visión emic de comunidad con el que ella elabora un relato teatral etic. Es decir, estudia el comportamiento del grupo para entender la representación ritual establecida de la mascarada y dirige un trabajo "dramantropólogico" (Prieto Stambaugh y Toriz Proenza 2015) que cristalizará en la representación de Alkimia 130. La obisparra como pre-treatralización (rito) es interesante no solo por sus valores estéticos, sino por la red de relaciones, conocimientos y maneras de pensar que confluyen en la representación y que

\footnotetext{
${ }^{6}$ Existe un vídeo casero de los años 70, probablemente de 1974 o 1975, recién recuperada la mascarada, y dos de TVE-CyL emitidos en 1989 y 1990, el primero en el programa Tele-Informe. Todos son un excelente documento.

7 Además de Mercedes Herrero, los actores Patxi Vallés, Trinidad Osorio, Alex Rodríguez, Raúl Gómez Paniagua y el técnico Alfonso Gómez Paniagua guiaron y acompañaron a los vecinos de Riofrío en la representación de La tenazada.
} 
hacen de ese "espectáculo" que se celebra el día uno de enero un acto cargado de sentido para los riofrienses. Esto no inhabilita a la performance de Alkimia 130 como comportamiento restaurado para estar llena de significados que se transmiten polisémicamente, tanto en el ámbito de las ideas estéticas como en el de las ideas socioculturales y políticas: trabajar el mundo rural y la autoestima de los lugares poniendo en valor lo que el otro te cuenta. En una entrevista, cuando la compañía se ha extinguido, Mercedes Herrero valora con perspectiva los trabajos en Riofrío y en otros pequeños pueblos. Sus palabras refrendan su activismo social:

Las personas que componíamos la tribu Alkimia nos preguntábamos quiénes éramos, qué cantos, qué objetos, qué trabajos habían llegado antes que nosotras y nos dimos de bruces con el mundo rural. Nos dimos con la tierra, el sol, el aire y mucho apoyo. El mundo rural nos dejó sus espacios, nos abrió sus conocimientos, nos acompañaron y les escuchamos. [...] A partir de lo que nos contaron construimos historias que ponían en valor sus modos de vida, sus oficios, su relación con la tierra y los animales, sus ritos y sus gentes. Sus espacios fueron y son muchas veces nuestros escenarios al aire libre, sus calles, sus eras o sus plazas. TierrAdentro, Raíces, Hilando. Filando, La Tenazada, historias creadas de gente para valorar su opción de vida (Delgado Pascual, 2017: 5).

No partimos de una oposición de contrarios entre lo real (el rito, la mascarada) y lo ficticio (la teatralización del rito) porque el rito se repite, pero cada año es único, y la teatralización puede entenderse, más que como una imitación de Los Carochos, como una recreación que generó una nueva ritualidad. Ambos, Los Carochos que se ejecutan cada uno de enero y La tenazada ejecutada una única vez, son actos performativos en sentido amplio porque ambos se ocupan del comportamiento humano dramatizado - recuperamos social drama de Turnery donde lo escénico convive con lo socio-cultural. La tenazada, además, utilizó el espacio de la mascarada que remeda y transforma — puertas de las casas, calles, plaza y río- y los actores, profesionales y no profesionales, ${ }^{8}$ prescindieron de butacas, telones, escenarios y cualquier elemento que impusiera una separación entre ellos y el resto del público. Todos a los que sin distinciones podemos

\footnotetext{
${ }^{8}$ Un nutrido número de riofrienses participó posteriormente en una teatralización de Los Carochos en la X Bienal de Restauración y Gestión del Patrimonio (ARPA) que se celebró en Valladolid en 2016 (Hidalgo Blanco et alii, 2017). Podemos entender esta actividad también como conducta restaurada.
} 
denominar participantes y por ello se integran en esta categoría desde los interpretes de los personajes de Los Carochos o de su recreación teatral hasta los artesanos de la indumentaria-máscaras, los ayudantes en la preparación y vestición y los que abren sus casas son actores liminares (ver Figura 7).

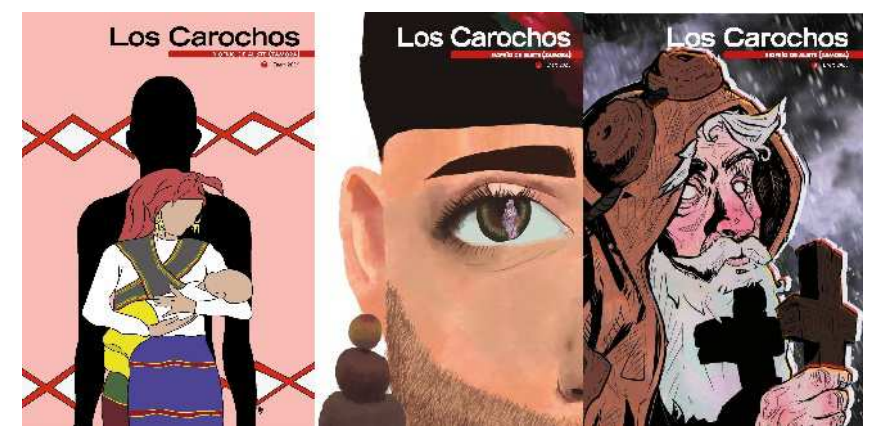

Figura 7. La revista Los Carochos se diseña desde la premisa de que la cultura popular no debe ser cerrada ni autosuficiente. Portadas de los años 2019-2021 que eligen diferentes personajes (la Madama, el Gitano y el Ciego) ilustradas por Estefanía Cifuentes, Michelle López y Héctor Fernández Blanco respectivamente.

Hacemos esta afirmación porque ellos - la comunidad de Riofrío en su mascarada y los "teatreros" de Alkimia 130 en connivencia con la comunidadrecrean una fiesta agraria antigua desde un tiempo moderno en el que la gestión de los tiempos de ocio y trabajo se hace desde la perspectiva urbana. Hablar hoy de "ciclo festivo" es un anacronismo (Panero García 2020: 9). En el nuevo contexto económico y social la máscara ha encontrado su lugar y podemos extrapolar la descripción que Néstor García Canclini hace para el uso del folklore en Hispanoamérica de trabajos que "renuevan la función sociocultural del arte y logran representar la heterogeneidad multitemporal", que mezclan "simultáneamente imágenes de la historia social y de la historia del arte, de la artesanía, de los medios masivos y del abigarramiento urbano" (1990: 343). Estamos ante hechos performativos en los cuales lo arcaico o tradición como estética e ideología del pasado son, en general, sublimados según la percepción postromántica. Esta se ha construido sobre la premisa de que la cultura tradicional se concibe radicalmente en oposición al ámbito culto y urbano. Sin embargo, Los Carochos fueron recuperados por los jóvenes en 1972 cuando muchos trabajaban o estudiaban en las ciudades, pero que creyeron en sus valores 
étnicos entendidos estos como la figuración del bien. Los jóvenes reciclaron la cultura dotándola de otro valor social como explican sin idealizaciones los "testigos directos", iniciativa que ha resultado ser un éxito, casi medio siglo después (AA.VV. 2021: 13).

La paradoja radica en que cultura moderna se consumó negando los territorios y sus tradiciones y en la postmodernidad el arte todavía aspira a ofrecer innovaciones valiéndose del pasado no convencional representando "la última diferencia legítima" (García Canclini 1990: 48). Esta posición implica concebir el arte como algo abierto que mantiene una posición crítica con el entorno hegemónico y bien encasillado, de cuyos márgenes es preciso salir si se quiere producir obras significativas. El desarraigo profesional educa la mirada distanciándose para participar con otra perspectiva:

Y yo me pregunto si La tenazada e Hilando filando fueron teatro contemporáneo, me pregunto si dar protagonismo a una comunidad rural en tiempos en que lo pequeño y lo no tecnológico está en proceso de desvalorización es contemporáneo, si fusionar el arte del hilado y la danza es contemporáneo, si proyectar sobre los adobes es contemporáneo, si homenajear a quienes llegaron antes y mantuvieron el rito vivo es contemporáneo, si unir arte y vida es contemporáneo. Mi respuesta es positiva, se hizo teatro contemporáneo porque fusionamos lo antiguo y lo moderno, y esto nos hizo valorar la esencia del rito ancestral en el aquí y ahora (Herrero Pérez 2013: 3).

Pero al mismo tiempo los retazos de la antigua cultura popular se concretan en el presente de la sociedad globalizada con las herramientas de proyección internacional del nuevo orden. Damos un dato revelador acerca de cómo funciona el grupo mantenedor de esta mascarada. En la preparación del no 9 de la revista Los Carochos (2021) que edita la Asociación Cultural "Amanecer de Aliste" y recoge toda la información del año precedente han participado más de cuarenta personas de las cuales no todas viven en Riofrío, sino en ciudades. Estas personas trabajan por la tradición local desde las estrategias que impone la sociedad moderna global. ${ }^{9}$ Cualquier actividad relacionada con la fiesta y con la

${ }^{9}$ El último número (2021) incluye las colaboraciones de dos fotógrafos extranjeros la alemana Iwajla Klinke y el francés Yannick Cormier-, una entrevista a la reconocida pintora portuguesa Balbina Mendes y la firma, también portuguesa, de António Jorge. La vocación internacional y nacional convive con la de mantener la memoria local. 
recuperación de la identidad étnica posee una función sociabilizadora que se pierde en las ciudades donde se vive y se trabaja. Esta función que se recupera en el lugar de vacaciones o en el pasar fines de semana, está asociada a los antepasados que vivieron cuando la sociedad sí era campesina y celebraba ritos agrarios, pero también con el uso presente de las redes sociales (ver Figura 8).

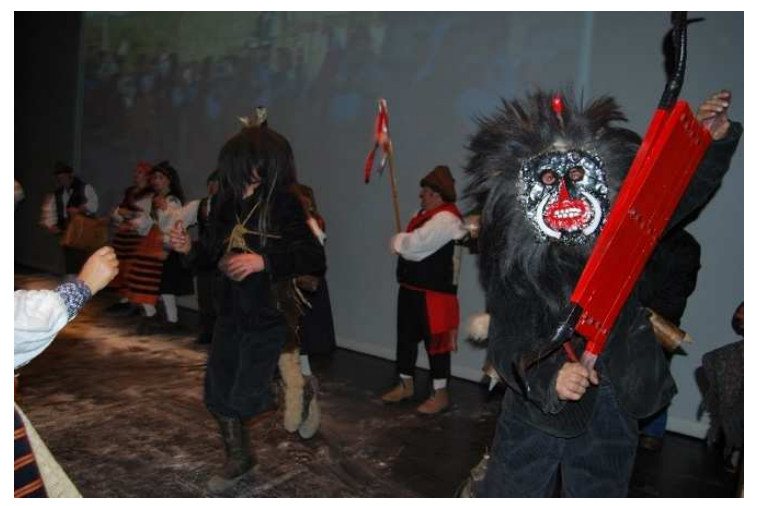

Figura 8. Después de las teatralizaciones de Alkimia 130 la comunidad hizo otra en la X Bienal de Restauración y Gestión del Patrimonio (ARPA). Han propiciado también la creación de una ópera y una película recreando su mascarada, distintas exposiciones, etc. Fotografía de Isaac Macho.

\section{MASCARADA Y TEATRO}

La arquitectura dramática abierta (no aristotélica) que crea Alkimia 130 es a imagen y semejanza de la mascarada y se divide en escenas yuxtapuestas, aunque en el rito sí hay acciones simultáneas como, por ejemplo, cuando los guapos inician la petición del aguinaldo mientras los filandorros se pelean con los carochos o cantan y bailan. Las escenas que representó la compañía están determinadas por cuatro espacios emblemáticos — portón de la calle Fonda (donde siempre comienza la mascarada), plaza del "Sagrao" (donde está la iglesia), plaza del "Sagrao" al río y ribera-río-puente - a su vez se fragmenta en cuadros. En estos espacios suceden escenas importantes de la mascarada, aunque ésta se desarrolla en todo el núcleo urbano de Riofrío. Cada escena corresponde a una idea esencial de la mojiganga que se nutre de otras ideas subordinadas $o$ secundarias en cada cuadro (Tablas 2, 3 y 4 ). 


\begin{tabular}{|c|c|c|c|}
\hline \multicolumn{4}{|c|}{$\begin{array}{l}\text { La tenazada }{ }^{10} \\
\text { Escena 1: HOY: AÑO NUEVO-AÑO VIEJO } \\
\text { Portón calle Fonda /Ayuntamiento/ Casas }\end{array}$} \\
\hline Cuadro 1 & Cuadro 2 & Cuadro 3 & Cuadro 4 \\
\hline $\begin{array}{l}\text { Personajes: mujeres hombre } \\
\text { anciano y niñas, hombre jóvenes } \\
\text { carochos. indumentaria } \\
\text { Elementos: palos de paloteo, } \\
\text { tradicional, palos } \\
\text { cohetes (2) máscaras, caracola, } \\
\text { máscaras, casa-máscara, fórmula } \\
\text { de felicitación, grito-silencio. } \\
\text { Acciones: Las mujeres hacen un } \\
\text { círculo con paloteo para que el } \\
\text { hombre anciano y las niñas } \\
\text { llaman a la puerta. } \\
\text { Se abre el portón en silencio, } \\
\text { alzan sus máscaras y gritan. } \\
\text { Progresivamente los carochos se } \\
\text { vuelven al público con sus } \\
\text { máscaras y formulan la } \\
\text { felicitación. }\end{array}$ & $\begin{array}{l}\text { Personajes: informantes en las } \\
\text { ventanas, cartero } \\
\text { Elementos: canción (estribillo E. } \\
\text { Parra), tamboril, censo de 2007, } \\
\text { campana. } \\
\text { Acciones: Desde una ventana un } \\
\text { personaje canta la canción. El } \\
\text { cartero toca la campana y comienza } \\
\text { a leer todos los nombres del censo. } \\
\text { Los personajes de las ventanas a } \\
\text { modo patio de vecinos hablan de los } \\
\text { carochos y se van intercalando } \\
\text { entre los parlamentos más nombres } \\
\text { del censo. } \\
\text { Cantan todos la canción y con una } \\
\text { campana avisan a los niños y niñas } \\
\text { (pequeños carochos) para que se } \\
\text { acerquen. }\end{array}$ & $\begin{array}{l}\text { Personajes: niños-niñas, músicos, } \\
\text { cartero. } \\
\text { Elementos: tenazas, cortinas de } \\
\text { puertas, máscaras, fórmula de } \\
\text { felicitación, redondilla (estilo } \\
\text { teatro del absurdo, bretchiana). } \\
\text { Acciones: Los niños y niñas } \\
\text { carochos abren camino con sus } \\
\text { pequeñas tenazas a los músicos. } \\
\text { Se acercan a tres puertas que } \\
\text { representan los elementos de la } \\
\text { máscara: boca y dientes, dos ojos, } \\
\text { nariz con colmillos. Delante de } \\
\text { cada puerta bailan una coreografía } \\
\text { y un actor dice la redondilla. } \\
\text { Se dice la fórmula de felicitar y la } \\
\text { última coreografía se hace delante } \\
\text { de un telón. }\end{array}$ & $\begin{array}{l}\text { Elementos: telón blanco. } \\
\text { Acciones: proyección de } \\
\text { sombra de carocho, } \\
\text { proyección de vídeo. El } \\
\text { vídeo es un corto grabado } \\
\text { por la compañía teatral } \\
\text { en el que el carocho de } \\
2008 \text { entrenaba los días } \\
\text { previos. }\end{array}$ \\
\hline
\end{tabular}

Tabla 2. Elaboración de la autora siguiendo el guion de Mercedes Herrero.

${ }^{10}$ Estética lograda con los colores negro, rojo y blanco, los de la carocha o máscara del Diablo Grande o Carocho. Además, hay otros efectos producidos por la iluminación y la música. 


\begin{tabular}{|c|c|c|c|c|c|}
\hline \multicolumn{6}{|c|}{$\begin{array}{l}\text { La tenazada } \\
\text { Escena 2: HOMENAJE } \\
\text { "Sagrao" }\end{array}$} \\
\hline Cuadro 1 & Cuadro 2 & Cuadro 3 & Cuadro 4 & Cuadro 5 & Cuadro 6 \\
\hline $\begin{array}{l}\text { Personajes: } \\
\text { cartero, tres } \\
\text { actores subidos } \\
\text { en escaleras. } \\
\text { Elementos: } \\
\text { tenazas, } \\
\text { altavoces, } \\
\text { escaleras, censo } \\
2007 . \\
\text { Acciones: } \\
\text { El cartero } \\
\text { continúa leyendo } \\
\text { el censo. } \\
\text { Los periodistas } \\
\text { voceros relatan } \\
\text { sucesos del año. }\end{array}$ & $\begin{array}{l}\text { Personajes: } \\
\text { Carochos, vecinos. } \\
\text { Elementos: grito, } \\
\text { cencerros, listado de } \\
\text { carochos y } \\
\text { preparadores de } \\
\text { carochos, espráis. } \\
\text { Acciones: } \\
\text { Los carochos con sus } \\
\text { máscaras votan y } \\
\text { hacen sonar los } \\
\text { cencerros, uno a uno } \\
\text { pone su máscara y se } \\
\text { para. lon nombres } \\
\text { Se leen los } \\
\text { de los que fueron } \\
\text { carochos y sus } \\
\text { preparadores. } \\
\text { Con los espráis se } \\
\text { hacen grafitis } \\
\text { (tenazas). }\end{array}$ & $\begin{array}{l}\text { Proyección de } \\
\text { vídeo donde } \\
\text { miembros de la } \\
\text { comunidad relatan } \\
\text { sus experienciasy } \\
\text { parecer acerca de } \\
\text { los carochos. }\end{array}$ & $\begin{array}{l}\text { Personajes: } \\
\text { mujeres. } \\
\text { Acciones } \\
\text { (procesión de la } \\
\text { vida): las mujeres } \\
\text { cantan y bailan. } \\
\text { Cuando terminan } \\
\text { aúllan dos lobos. }\end{array}$ & $\begin{array}{l}\text { Personajes: cinco } \\
\text { personajes } \\
\text { mujeres. } \\
\text { Elementos: alpacas } \\
\text { con cuerdas, ataúdes, } \\
\text { tierra y palas, } \\
\text { instrumentos } \\
\text { musicales, candiles. } \\
\text { Los cinco personajes } \\
\text { tiran de los ataúdes, } \\
\text { los carochos llegan } \\
\text { con sus cencerros y } \\
\text { la muerte es parada } \\
\text { por las mujeres. Se } \\
\text { hace un círculo de } \\
\text { tierra y dos de ellos } \\
\text { son metidos en los } \\
\text { ataúdes. Encienden } \\
\text { barras y palos } \\
\text { dobles. }\end{array}$ & $\begin{array}{l}\text { Personajes con } \\
\text { fuego, carochos } \\
\text { y público. } \\
\text { Elementos: } \\
\text { fuego, cadenas, } \\
\text { un mandala, } \\
\text { títere-máscara. } \\
\text { Acciones: Los } \\
\text { lobos aúllan. Los } \\
\text { diablos } \\
\text { "abarruntan" a la } \\
\text { muerte de ese } \\
\text { año y luchan } \\
\text { con el fuego. } \\
\text { El títere queda } \\
\text { respirando. }\end{array}$ \\
\hline
\end{tabular}

Tabla 3. Elaboración de la autora siguiendo el guion de Mercedes Herrero. 


\begin{tabular}{|c|c|c|c|}
\hline \multicolumn{4}{|l|}{ La tenazada } \\
\hline $\begin{array}{l}\text { Escena 3: } \\
\text { EMBESTIDA } \\
\text { Calle del "Sagrao" al río }\end{array}$ & $\begin{array}{l}\text { Escena 4: } \\
\text { MAÑANA: EL FUTURO DE LA TRADI } \\
\text { Río-puente }\end{array}$ & IÓN & \\
\hline Cuadro 1 & Cuadro 1 & Cuadro 2 & Cuadro 3 \\
\hline $\begin{array}{l}\text { Personajes: } r \text { Carocho } \\
\text { Grande, carochos y cinco } \\
\text { personajes portando } \\
\text { "pájaros" (barras con } \\
\text { fuego). } \\
\text { Elementos: humo, pájaros, } \\
\text { cencerros y tenazas. } \\
\text { Acciones: Los carochos } \\
\text { hacen la embestida juntos y } \\
\text { la cabeza el Carocho } \\
\text { Grande. Recogen los } \\
\text { instrumentos y se meten en } \\
\text { una casa. }\end{array}$ & $\begin{array}{l}\text { Personajes: los de la procesión y el } \\
\text { público, carochos, Carocho Grande, } \\
\text { hombre anciano y niñas. } \\
\text { Elementos: tenazas y máscara del } \\
\text { Carocho Grande. } \\
\text { Acciones: los carochos dejan las tenazas } \\
\text { en círculo en el suelo y se van } \\
\text { colocando delante de la ribera para } \\
\text { pasar el río. El hombre anciano y las } \\
\text { niñas van hacia el puente. El Carocho } \\
\text { Grande aparece desde una calle, se } \\
\text { coloca delante del anciano y deja sus } \\
\text { atributos (máscara y tenazas) al hombre } \\
\text { y grita. Los demás carochos pasan el río } \\
\text { gritando y se van calle arriba hasta no } \\
\text { ser vistos. }\end{array}$ & $\begin{array}{l}\text { Personajes: anciano, niñas y } \\
\text { coro de mujeres. } \\
\text { Elementos: tenazas y } \\
\text { carocha. } \\
\text { Acciones: El anciano deja la } \\
\text { carocha y las tenazas a las } \\
\text { niñas y se va por el puente } \\
\text { hasta desaparecer en las } \\
\text { tinieblas. Las mujeres } \\
\text { cantan el fragmento de la } \\
\text { canción de Eliseo Parra. }\end{array}$ & $\begin{array}{l}\text { Personajes: todos. } \\
\text { Elementos: comida y } \\
\text { bebida. } \\
\text { Acciones: regresan los } \\
\text { carochos con bandejas de } \\
\text { comida y se celebra una } \\
\text { fiesta con música y baile. }\end{array}$ \\
\hline
\end{tabular}

Tabla 4. Elaboración de la autora siguiendo el guion de Mercedes Herrero. 


\section{LA PALABRA}

Como en la mascarada en la performance de Alkimia 130 prevalece la acción sobre la palabra, aunque la oralidad es muy importante en varios momentos del rito: en la salida con la fiscalización a los filandorros por parte de los vecinos; en el bautizo del Niño de la Madama como purificación de la comunidad a través de la savia nueva; en el desarrollo de las penurias de los filandorros y, posteriormente, con las canciones liberadoras de los males que han afligido durante el año tras la "resurrección" del Ciego; y, sobre todo, con la participación de todos los vecinos en la felicitación y parabienes. La visita a todas las casas y la fórmula se repite continuamente por todos sin excepción que van interactuando con los cuatro grupos de personajes.

La recreación del rito de La tenazada mantiene la palabra esencial de la fórmula de felicitación e incorpora otra oralidad. Esta está destinada a preservar la memoria local desde dos ópticas reconocer a la comunidad en su conjunto, con mención especial a los que encarnaron al Carocho Grande, y visibilizar el relato que los habitantes de Riofrío elaboran en torno al personaje; pero también explicar la tradición (del lat. traditio, -onis) derivado del verbo tradere, que significa transmitir o entregar.

La fórmula ritual tradicional de felicitación que se dice absolutamente en todas las casas el día de Año Nuevo con una función profiláctica. La decían los personajes de la mascarada al pedir el aguinaldo (Rodríguez Pascual 2009: 137):

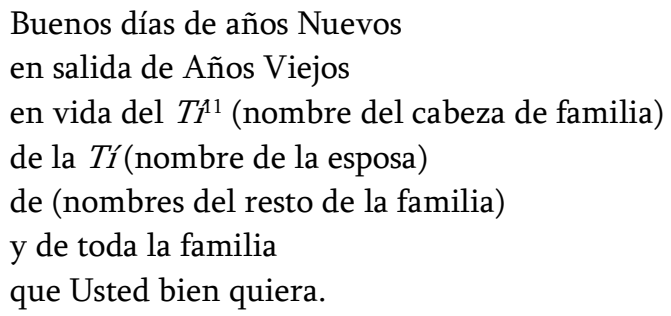

A la que los anfitriones respondían con cortesía "Qué de hoy en un año", para después desearles salud para celebrar la fiesta muchos años. Solamente se evitaba la fórmula consuetudinaria en las casas en las que había ocurrido una muerte (Rodríguez Pascual 2009: 141) en las que se rezaba una oración pues no se pedía el aguinaldo. Hoy se acomoda a las formas actuales menos ceremoniosas, pero

${ }^{11} T i ́$ es apocope de tío o tía y hoy día en Aliste sigue siendo el tratamiento de respeto para las personas mayores. 
sigue conteniendo el deseo de fecundidad e insertándose en tiempo cíclico que se debe cumplir, a pesar de que los que participen organicen su año de manera lineal. En la teatralización se repite hasta dos veces en la primera escena, cuando todos los varones jóvenes como carochos se dirigen a la comunidad y cuando se representa el momento importante de llamar a las puertas de las casas. En la recreación se sustituyen los nombres del pater y mater familias por "en la vida de todo el pueblo", pero los buenos deseos de la fórmula consuetudinaria no pierden fuerza. De hecho, en nuestra opinión se podría eliminar cualquier parte del ritual, algunas han desaparecido o se han simplificado, excepto esta fórmula benefactora para todos los vecinos (Figura 9).

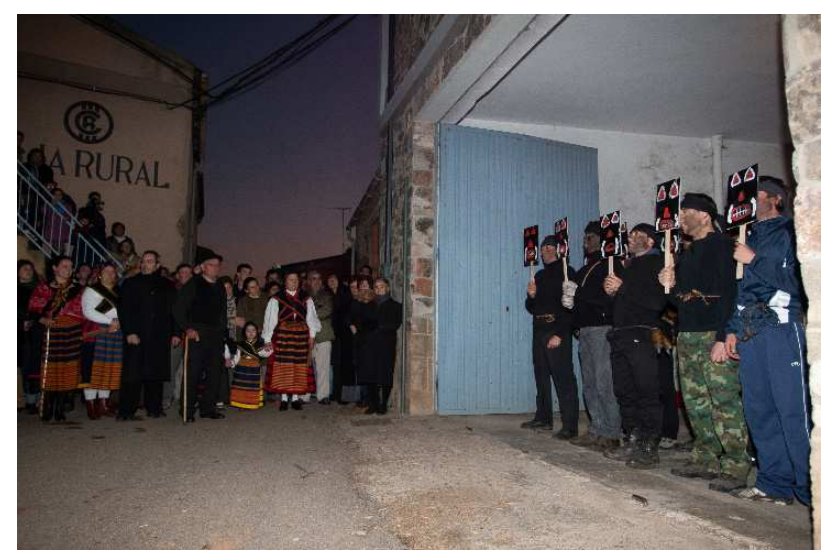

Figura 9. La performance de Alkimia 130 comienza donde la mascarada. Los varones jóvenes son los carochos y las mujeres, narradoras de la memoria, acompañan al anciano y a las niñas. Los carochos dirán por primera vez la fórmula benefactora y consuetudinaria. Fotografía de José Luis Leal.

La oralidad que se incorpora en la performance de Alkimia 130 es sencilla pero efectiva en la consecución de su fin, que es el de recrear la condición más importante de la mascarada: "Es un rito comunitario, respirando común", según lo expresa Mercedes Herrero (Entrevista, 13/09/2019). El comunalismo que relata un escritor en 1897, Santiago Méndez Plaza, usual en Aliste y en las comarcas limítrofes de ambos lados de La Raya, fue el armazón en el que se organizó la vida hasta bien entrado el s. XX. Hoy ha cambiado el modelo que mantenía una organización comunal como herramienta de supervivencia, pero pervive en la memoria colectiva a través de sus fiestas (Méndez Plaza, 2002: 95). Este jurista poco antes había escrito: 
En sus relaciones de igual á igual ya es otra cosa. La estrecha solidaridad en que viven podría servir de modelo práctico, si no de comprobación, á ciertas formas de organización, más menos comunistas, más ó menos colectivistas, ideadas por teóricos y reformadores para mejorar el presente estado de la sociedad. Merced á ella pueden resistir las infinitas causas de disolución, naturales y sociales, que conspiran á hacerles imposible aun la vida azarosa y llena de aflicciones y desasosiegos que arrastran (Méndez Plaza 1902: 24). ${ }^{12}$

En la primera escena performance se hacen presentes todos los vecinos en la fecha de la representación mediante la lectura del censo con un actor, que bien podría ser el antiguo pregonero de los pueblos, que comenzaba con esta fórmula en dos partes:

A 30 de diciembre de 2007 en vísperas de terminar el año, con la participación de las gentes del lugar y comediantes de otras tierras, trabajando con ahínco y gran esfuerzo.... estamos a punto de celebrar el homenaje al Diablo Grande o Carocho, esperemos sea de su agrado la representación y disfruten del espectáculo... todo sea por mantener la tradición viva.

A 30 de diciembre de 2007 en vísperas de terminar el año habitan este pueblo de Riofrío de Aliste .... habitan... (nombres censo).

El cartero se hace oír a toque de campana, instrumento fundamental que ha marcado la vida y la muerte, lo civil y lo religioso, de las gentes en función de si los toques eran religiosos o solidarios hasta la extinción de la cultura agroganadera (Alonso Ponga 2008: 106-144). Los nombres del censo se intercalan con una escena de teatro cómico popular, un grupo de vecinos en las ventanas comentan sus pareceres sobre quiénes son los diablos que aparecen en el Año Nuevo y desaparecen misteriosamente hasta el siguiente. Los comentarios de los vecinos están extraídos de las entrevistas que se realizaron durante la residencia por lo que son una verdad ficcionalizada (ver Figuras 10 y 11):

Mercedes: Son malos, malísimos.

${ }^{12}$ El texto se había publicado como tirada aparte de la Revista general de Legislación y Jurisprudencia en 1896, sección de Derecho Consuetudinario como indica Joaquín Costa en el prólogo al volumen. 
Alex: Qué van a ser malos, si reparten chorizo. Habrás visto tu algún diablo repartiendo chorizo.

Mercedes: Son demonios de la fertilidad.

Raúl: Eran los dioses de los pastores en la mitología romana.

Trini: Son espíritus de la naturaleza.

Raúl: Encarnan la fuerza y la naturaleza. Aunque el río esté crecido lo cruzan. Bueno,

les cuesta un poco... Les cuesta un poco, pero lo cruzan.

Alex: Está usted confundido. Se llevan el año viejo para traer el nuevo.

Trini: Son una tradición son una tradición.

Todos: Son una tradición...

[El cartero continúa recitando nombres censo mientras los personajes cambian de

ventana y hace sonar la campana]

Alex: ¿Por qué son demonios?

Mercedes: Porque no son santos.

Trini: Las tenazas eran un instrumento para repeler el mal.

Mercedes: Hay que tener cuidado con ellos porque te ponen negra, aunque no quieras.

Raúl: ¿Y si no vienen este año?

Trini: ¡Calla, calla! ¡No van a venir...! Si siempre han venido desde que la gente recuerda.

Cuando mi abuelo era pequeño ya había carochos.

Raúl: Pero, ¿y si no vienen?

Alex: Pues sentiríamos que estábamos cerraos. La gente quiere alegría.

[...nombres censo, campana]

Todos [comenzando de uno en uno cantan]:

"No me digas Urbana

que esto se va a perder,

para que no se pierda

me lo voy a aprender" (bis) 


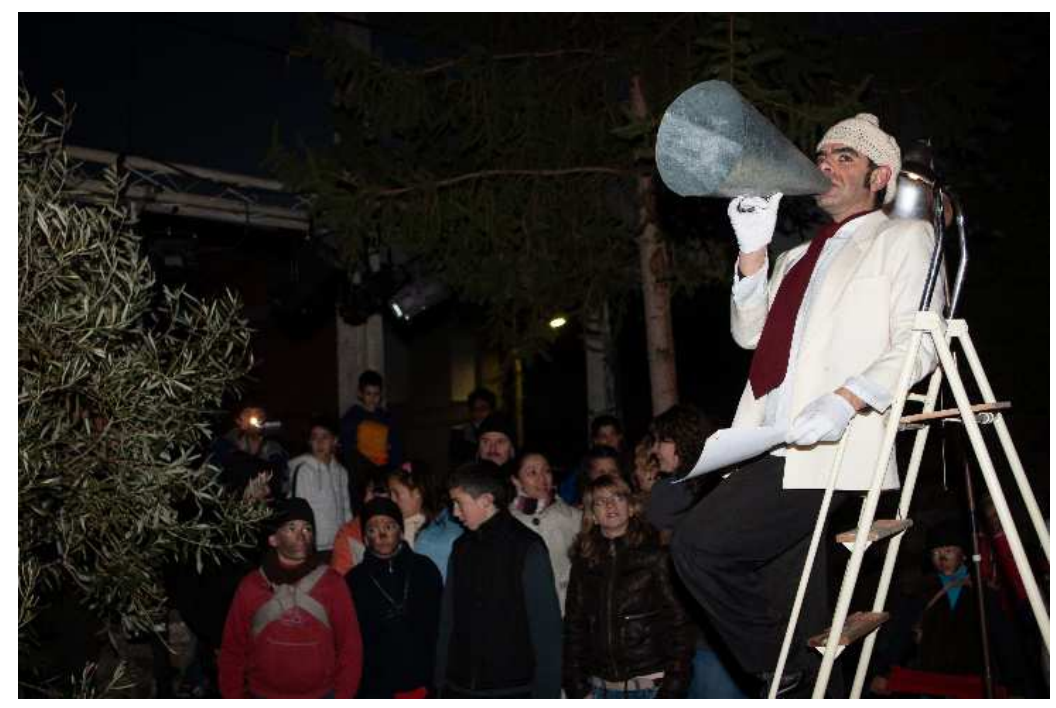

Figura 10. Un pregonero lee el censo municipal de 2007 y después nombra a todos los varones que han sido carochos en los últimos cuarenta años. Fotografía de José Luis Leal.

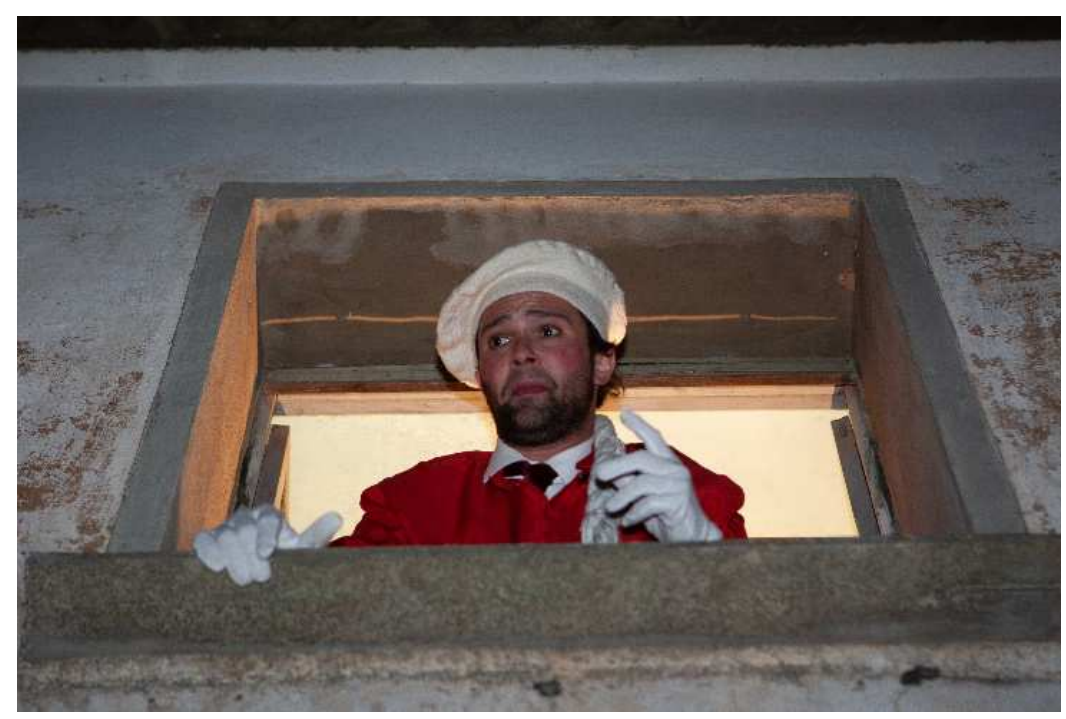

Figura 11. Desde las ventanas a modo de teatro cómico distintos "vecinos" expresan su parecer sobre los personajes más misteriosos de la mascarada. Fotografía de José Luis Leal. 
La copla o cantar final que ya han interpretado uno de los actores al comenzar la escena y ahora al final de ese pequeño sainete la cantarán las mujeres al final de la cuarta escena. Pertenece a la canción "Suite del Rebollar" del álbum Tribus hispanas (1998) del reconocido investigador, recopilador, divulgador y renovador de la música tradicional, Eliseo Parra, artista que ofrece la tradición como tradición de tradiciones. Los comentarios de los "vecinos" acerca del personaje refuerzan su carácter misterioso - "Cuando preguntas por la Filandorra todo se concreta, pero el Carocho...”, dirá Mercedes Herrero- y sus cualidades como démone, ser intermedio protector de los mortales y causantes de la fecundidad y, en consecuencia, de "alegría"; dan información sobre su instrumento, las tenazas, o sobre sus acciones, dan de comer chorizo, tiznan con las corchas...; y también la necesidad de que la costumbre se cumpla. El rito tiene carácter obligatorio y de su práctica necesariamente se derivarán consecuencias con una dimensión tangible o simbólica.

Todavía se hacen presentes de una forma más honda leyendo los nombres de los hombres que encarnaron al Carocho Grande en los últimos cuarenta años comenzando por Francisco Pérez Blanco, anciano que tendrá mucha relevancia en el comienzo y en el final de la teatralización y que representa la sabiduría de los mayores. También se leyeron los nombres de los preparadores de los diablos, encargados de vestirlos con todos sus atributos, que son esenciales. Con el censo se reconoce a los presentes, con los intérpretes de Carocho a los que están y los que no, y que han contribuido a que el grupo cambie y al mismo tiempo sea el mismo que mantiene la tradición:

Cuarenta nombres de carochos y, claro, a todos les atraviesa la familia, fue muy emocionante. Nombramos a quienes vistieron, que también es alguien que no se ve, pero que es muy importante. Ricardo [Brizuela] ya no está que es quien nos contó todo. Son esos acompañantes que están dentro de esa nave vistiendo, ayudando, preparando... (Entrevista a Mercedes Herrero, 13/09/2019).

En el rito en el que el grupo de filandorros celebra la resurrección del Ciego que tocará la zanfona mientras El Gitano y la Filadorra bailan y El Molacillo toca las conchas y canta coplas satíricas, picantes y jocosas del corpus popular y de los hechos acaecidos en el pueblo, en España o en el mundo puestos en solfa. Este personaje es encargado de la crítica social y en contra del tópico repetido el 
Carnaval tradicional, y este lo es, no es transgresor sino moralizante a contrario. En las coplas del Molacillo se censura lo que es pernicioso para el pueblo o reprobable moral y socialmente. La segunda escena de La tenazada estiliza este momento importante en el que la comunidad hace balance haciendo comentar a tres "periodistas" los sucesos más relevantes, también en un cuadro humorístico típico de teatro cómico popular (Figura 12):

Raúl: Se murieron las burras del Tí Augusto y el Tí Daniel... Qué en paz descanse ...y Los Carochos este año se han quedado sin burros para tirar del carro.

Trini: Una gran tormenta no dejo bailar en las fiestas de agosto.

Mercedes: El Día de Todos los Santos se volvió a celebrar la ceremonia de la lumbre, que no se celebraba desde que se marchó don Germán.

Trini: La matanza bien gracias, aunque el agua del río ayer bajaba algo fría para lavar las tripas.

Raúl: El 8 de diciembre nació Paula, la hija de Gumer y Ana.

Trini: Desaparecieron las vacas de Las Chanas.

Mercedes: En busca de las tierras perdidas a causa de la concentración parcelaria, la gente andaba loca buscando las tierras.

Raúl: ¡Novedad, creación de una nueva aula infantil!

Trini: Exposición sobre la esquila de las ovejas en la casa del médico.

Mercedes: Exposición de fotografía sobre la comarca de Aliste "8 miradas".

Trini: La semana pasada las mujeres triunfaron en Zamora cantando La cordera en la Iglesia de Santiago el Burgo.

Raúl: Noticia de última hora. No estoy muy seguro, pero creo que justo en estos momentos se está celebrando un chou sobre Los Carochos y aquí mismo...

Mercedes: ¿Qué me dices...? 


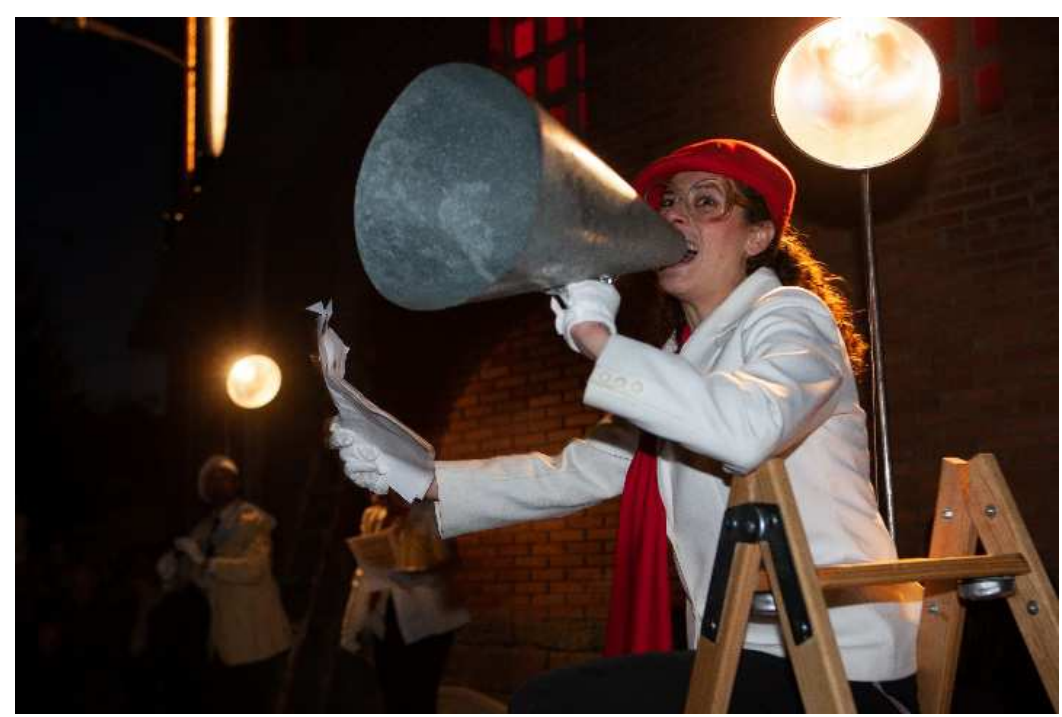

Figura 12. Los periodistas informan de los sucesos en Riofrío en el último año. Fotografía de José Luis Leal.

Existe otro momento en el que la palabra es utilizada en el rito sustentando "la sustracción de la cotidianeidad del objeto", práctica común en las performances. En este caso el "proceso semiótico de desrealización, desdoblamiento, denegación" (Abraham 2008: 83) se hace con dos objetos fundamentales del rito: las puertas de las casas que en esta ocasión tienen unas cortinas y la máscara del Diablo Grande.

Hacia el final de la primera escena los niños y niñas bajan por la calle principal abriéndose paso entre los músicos y pasan. Las puertas de las casas simbolizan la entrada al espacio doméstico, pero también el propio espacio que es parte del pueblo. Además, se asocian con Jano, el dios bifronte que encarna la salida y la entrada de las que es su guardián, y es en la puerta donde todos los grupos anuncian la salida del año y la prosperidad para el nuevo cada 1 de enero. La máscara del Diablo Grande representa la presencia de una entidad sobrenatural que transforma al que la lleva y por ello, al menos en origen, eran un elemento religioso por lo que es parte esencial del rito. En una puerta se representan la boca y los dientes del Carocho Grande, en otra los ojos y en otra los colmillos y nariz. Estos elementos expresionistas de la carocha respaldan el carácter benéfico del demonio (daimôn) pues la boca simboliza el hálito de la vida pues de misma nacen los dioses; los dientes la virilidad y la capacidad de procreación; los ojos la 
luz y la capacidad de visión espiritual; y la nariz la apertura a la vida. Delante de cada puerta los niños hacen una coreografía mientras que el cartero tira de la cortina que tiene uno de los sentidos de la máscara y recita una redondilla disparatada e ilógica en la línea del estilo del teatro del absurdo:

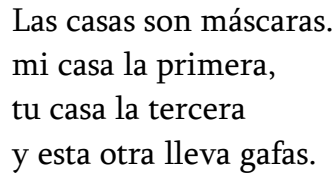

Con este uso de los objetos se le da un carácter ficcional a unos elementos que previamente formaban parte de la pre-teatralización, pero con la palabra utilizada no de forma lingüística en sentido estricto. El público conoce los signos en la literalidad del rito como partes de la máscara, pero aquí se abren a la interpretación libre. Los materiales son previos, pero se han cortado y recompuesto con una ideología y una estética nueva que aviva el discurso polisémico de la máscara.

\section{LA ACCIÓN HIPERITUAL}

Si la mascarada se celebra en un contexto lúdico, la recreación La tenazada sigue la misma estela, aunque con un componente emotivo que en la mascarada se produce en las casas, pero no en las calles donde prima lo bullanguero. Hemos apreciado que existe una emoción alegre cuando los jóvenes que hacen la función de la mascarada entran en los hogares, pero no en la calle donde las acciones cómicas, rápidas, caóticas y ruidosas solo dejan espacio a la diversión. Este hecho no invalida que el resto del año se reflexione de forma pausada sobre su sentido y se trabaje en muchas acciones destinadas a perpetuar la etnohistoria y el rito que las siga generando. Un ejemplo es la Casa de Los Carochos (Museo), por mencionar uno que está orientado a conservar el patrimonio de los antepasados en clave de tradición étnica y personal. Esto lógicamente implica una emoción diversificada en sentimientos de identidad y de arraigo local y familiar a través de las historias de vida, pero también una emoción estética. En cualquier caso, la emoción no es nunca ajena al rito:

en la actividad ritual, las relaciones en el espacio y el tiempo son, ante todo, relaciones entre unos y otros, o entre uno y otro, o entre uno y los otros. La relación con el tiempo y el espacio, en la actividad ritual, es 
siempre una relación con los otros. Esta relación puede entenderse de dos modos. Por una parte, la celebración ritual tiene siempre como telón de fondo una colectividad que se pone en escena de una manera $u$ otra. La conciencia de que esta colectividad existe y la conciencia de formar parte de ella contribuyen a la emoción que suscita $\mathrm{y}$, eventualmente, a la confianza que conlleva (Augé 2004: 98).

Hablamos de acción o representación hiperitual (rito en segundo grado) porque el guion de Alkimia 130 se comprende desde la conciencia de que existe un hiporito (fuente principal) parafraseando el célebre libro sobre teoría literaria de 1982 de Gerad Genette (1989). La tenazada se comprende por la presencia de Los Carochos, que son convocados por ella continuamente. Pensamos en una acción hiperitual porque existe la conciencia de que los dos hechos performativos se superponen en sus enunciaciones, tanto en el registro serio como en el cómico, en el transcurso de la representación teatral.

Algunas de las acciones rituales de la fuente original se mantienen en La tenazada como los que otorgan sabiduría y abundancia por medio de la palabra, los de purificación y purga mediante el fuego y las luchas de opuestos mediante las peleas. Otros como los de iniciación o paso no se dan, porque ni siquiera tienen sentido en la mascarada dado que el colectivo de mozos no existe.

En La tenazada estarán los elementos que dotan simbólicamente a la mascarada de un sentido, los de la máscara ya los hemos visto asociados a la redondilla brechtiana, combinados con la danza o expresión corporal, la música, las artes plásticas, el teatro, la literatura y los audiovisuales. Podemos hablar del uso de un lenguaje icónico.

En la mascarada hay elementos de estas disciplinas, total o parcialmente pues El Galán toca las castañuelas, El del Tambor el tambor, el Ciego la zanfona, el Molacillo las conchas y la caracola y, al final, hay un baile con un gaitero y otros músicos; pero en la performance teatral las licencias son muchas. Por ejemplo, en la acción se intercala la copla en heptasílabos de Parra que, junto con la seguidilla, son los poemas estróficos populares más cantados (coplas y jotas), pero se combina con la música punki en la segunda escena (procesión de la muerte) que se torna música tranquila al final de la misma escena y también se utiliza la música cuando se leen los nombres de todos los que han sido en Diablo Grande. Cuando las mujeres cantan, por ejemplo, en la procesión de la vida, se utiliza la forma popular. Y lo mismo sucede con los sonidos, pues tienen mucha 
importancia los cencerros y los gritos de la mascarada, pero se añaden otros: aullidos de lobos y el sonido del yunque de una fragua. Los gritos no los da solo el Carocho Chiquito, sino que son comunitarios, al igual que los cencerros, que no son privilegio exclusivo de dos, sino de todos los carochos de la performance.

La tenazada comienza con las mujeres que ejecutan una danza de paloteo para abrirle el paso al hombre anciano, testigo autorizado del devenir de los carochos, con dos niñas que no saben nada de ellos. El paloteo, que es danza esencial de muchas celebraciones como las de la Virgen del Rosario o el Corpus Christi, no forma parte de Los Carochos, pero sí de otras mascaradas de invierno ejecutadas por varones como la de Constantim en A festa das morcelas ou da mocidade con un personaje llamado Carocho como enmascarado y sustituyendo palos cayadas en otras como A festa do Santo Menino en Tó (Tiza 2013: 115-116; Díaz Lorenzo et alii, 2020:15, 29).

Los hombres jóvenes, y entendemos jóvenes en el sentido laxo actual, en varios momentos le dan movimiento a la performance con su cuerpo, se cubren con la máscara o se descubren, mueven las tenazas, saltan haciendo sonar sus cencerros y gritan. La expresión corporal es muy importante en la segunda escena donde los varones carochos se van poniendo la máscara y dejan de saltar a medida que se dicen los nombres de los que han sido carochos (Figura 13). Los niños y niñas hacen lo mismo que los varones carochos, pero además ejecutan una coreografía delante de cada una de las tres casas-máscaras (Figura 14). Las mujeres bailan mientras cantan bajando unas escaleras del "Sagrao" en el cuadro de la procesión de la vida, como lo harán en momentos previos al desenlace en la segunda escena del último cuadro (Figura 15). En la procesión de la muerte el movimiento con las alpacas con las que se arrastran ataúdes e instrumentos mantiene el ritmo de la acción a medida que se incorporan otros elementos como la tierra y la pala, los candiles y las barras con fuego (Figura 16). 


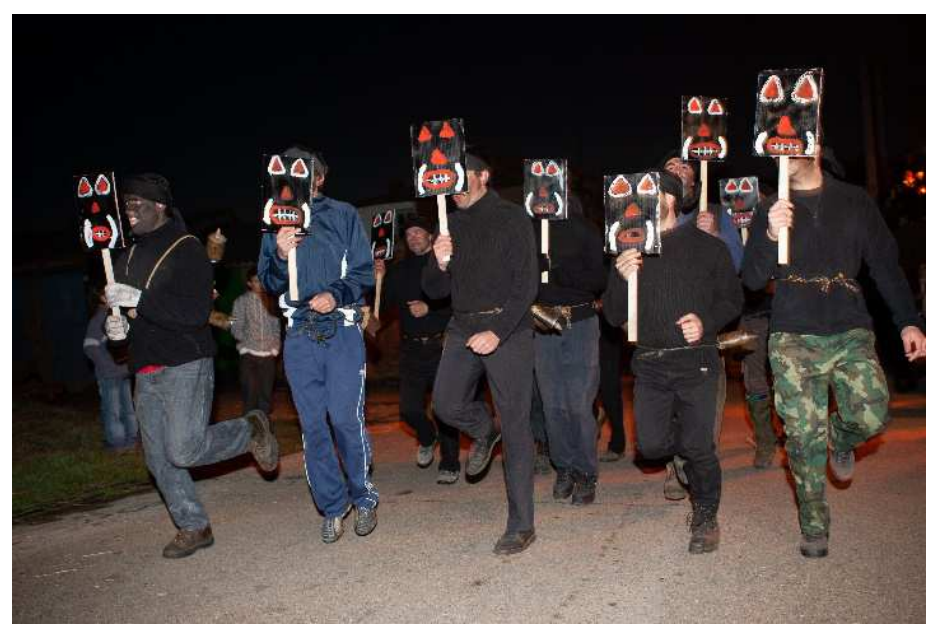

Figura 13. La expresión corporal es muy importante, Los carochos saltan con sus cencerros ya en la ribera del río. Se preparan para la pelea. Fotografía de José Luis Leal.

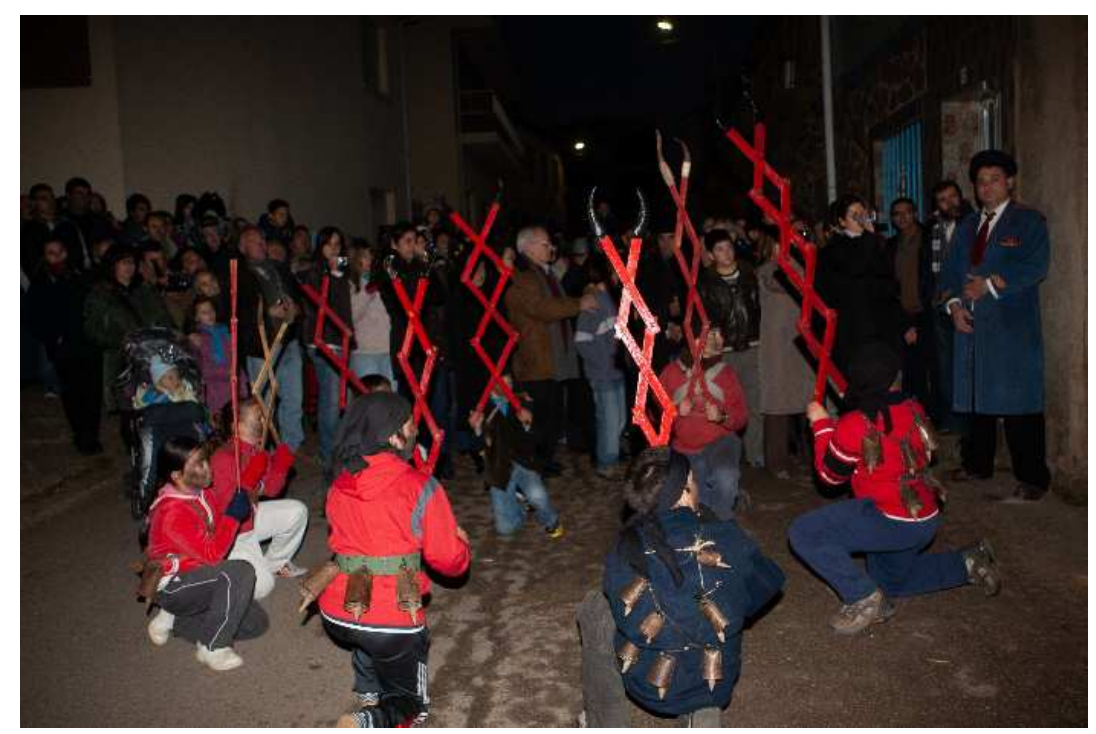

Figura 14. Los niños y las niñas hacen una coreografía delante las puertas-máscaras en presencia del cartero que los ha llamado a toque de campana. Fotografía de José Luis Leal. 


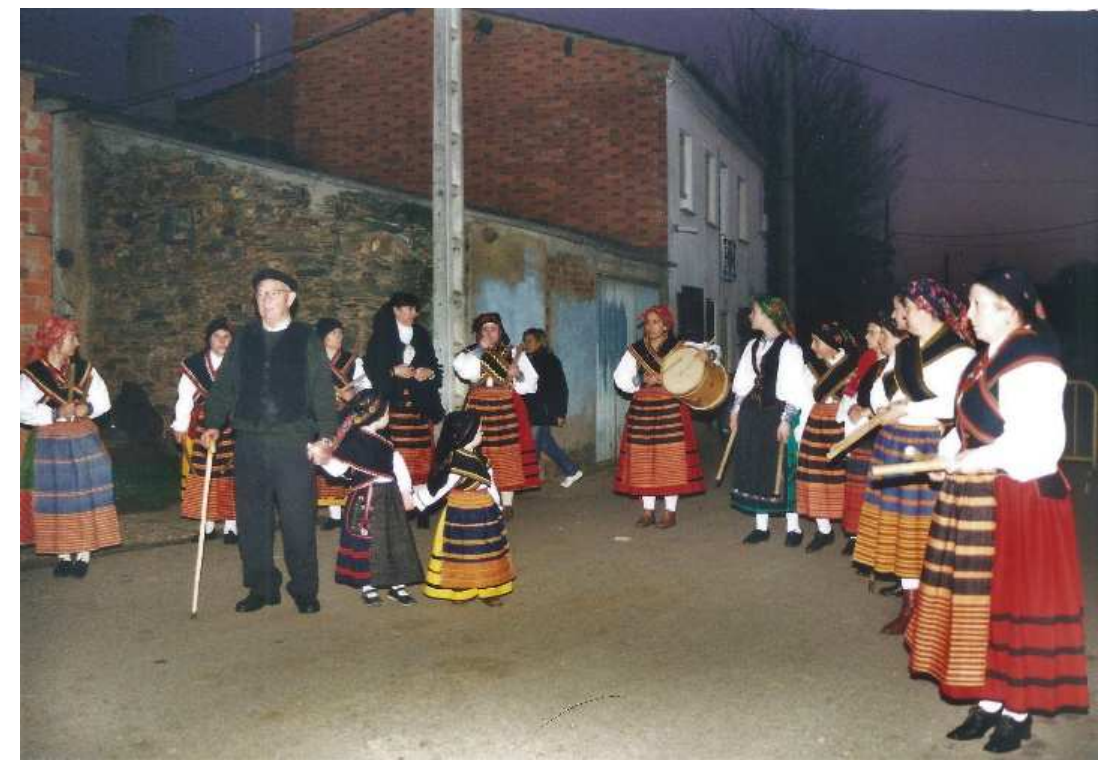

Figura 15. Las mujeres cantan y bailan en la procesión de la vida. Las acompaña Francisco González con las niñas Ainhoa y Almudena. Fotografía de Emilio Gallego.

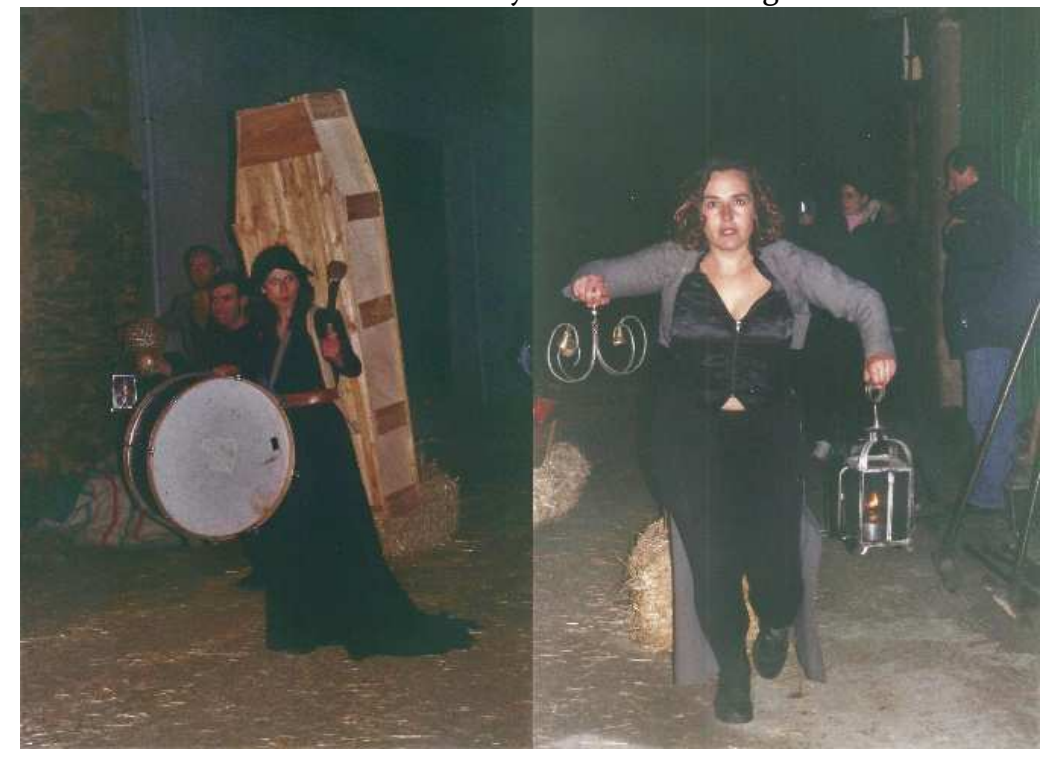

Figura 16. Dos momentos de la procesión de la muerte. Fotografías de Emilio Gallego. 
Una de las acciones de la mascarada que es importante en la representación es la lucha de opuestos mediante peleas. En la mascarada los carochos se pelean con los ciegos o filandorros, aquí la pelea la hacen con los representantes de la muerte. Estos se diferencian por las barras de hierro con fuego, primero, y cadenas, después, y entablarán una lucha con todos los carochos que aparecen con sus tenazas desde distintas calles asustando al público. En la lucha se asocia simbólica y estéticamente al Carocho Grande un elemento importante en la obisparra que es el humo, que en la representación está hasta cinco veces y es de distintos colores. En la última de las peleas, además de todos los varones carochos uno se diferencia porque lleva la máscara que se utiliza en el rito (ver Figura 17).

Las artes plásticas están presentes en la representación sin olvidar la importancia que los artesanos de máscaras y tenazas en este caso. En la escena segunda mientras se leen los nombres de los que han sido carochos personas de diferentes edades hacen con espráis grafitis que representan las tenazas. Distintas iluminaciones en blanco, negro y rojo contribuyen a crear una atmosfera especial en las calles que pierden su cotidianidad para ser el lugar de la representación.

En el hiperrito también se utilizan los audiovisuales para proyectar la sombra del Carocho Grande y dos vídeos. El primero es un corto grabado por la compañía teatral en el que el joven que sería el Diablo Grande dos días después de representación, ya en 2008, entrenaba. Actualmente los entrenamientos se han relajado porque el joven que lo encarna se rige por el ritmo de vida moderno y estudia o trabaja. Sin embargo, en la sociedad tradicional era frecuente escuchar de noche al personaje dar carreras los días previos con la máscara y las tenazas. Su interpretación requiere una gran fortaleza física porque el aparejo de los cencerros pesa mucho, la máscara que sujeta con la boca mordiendo con fuerza dificulta la visión y las tenazas también son pesadas y limitan el movimiento. A esto hay que sumar los dos momentos, uno de ellos en la salida, en la que de su espalda sale humo, antes se encendía una mecha de las utilizadas en las canteras de pizarra y actualmente botes de humo, que complican el movimiento. El vídeo evoca las carreras del Carocho en la noche que anticipaban la celebración de la fiesta. El segundo vídeo refrenda lo que los actores de la compañía han interpretado en la escena cómica, pero aquí los miembros de la comunidad son los que relatan sus experiencias con ellos desde el temor en la infancia a las creencias e ideas que les sugieren. 


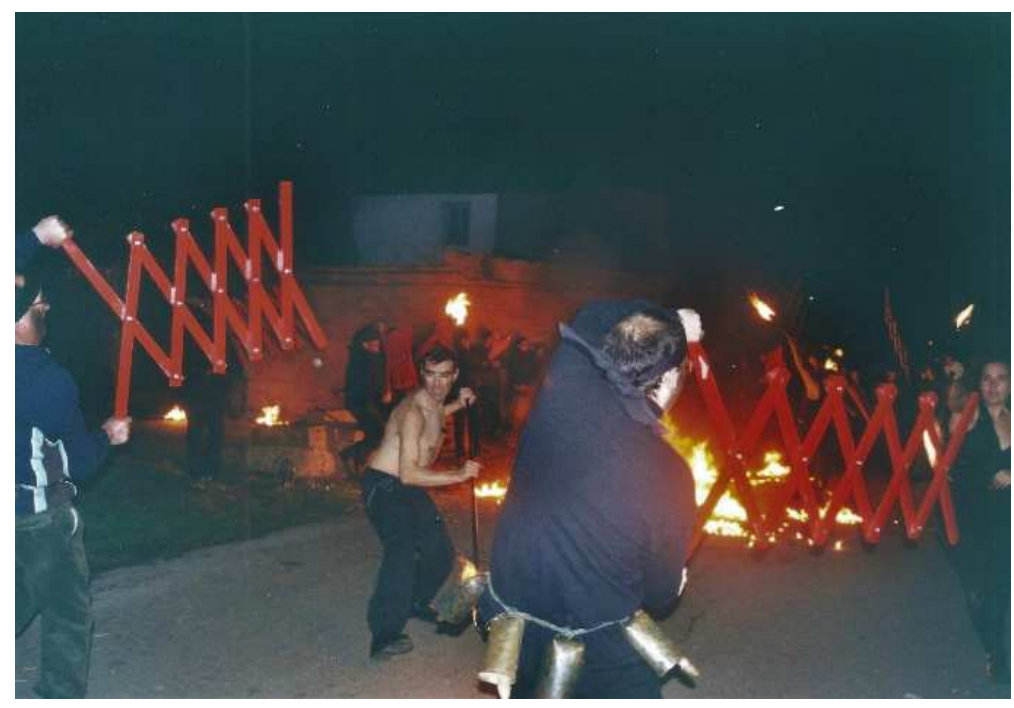

Figura 17. Los carochos con sus tenazas repelen los males de la comunidad y traen abundancia. Fotografía de Emilio Gallego.

Las últimas acciones están cargadas de simbolismo. Se recogen todos los objetos de las luchas previas y pasan los carochos con los personajes que portan los pájaros del fuego, elemento que se utiliza para ir delimitando los espacios, llega toda la gente al puente y los carochos se paran mirándolo en los dos extremos de la calle, el anciano y las niñas se dirigen al puente, los carochos depositan sus tenazas en un círculo y se van colocando en la ribera para después cruzar corriendo el río. Con el paso del río recuperan un elemento importante del rito cuando los dos Carochos se purifican en el Año Nuevo con el agua. Se avisa al joven vestido con la indumentaria y la máscara del carocho real que llega corriendo, haciendo sonar sus cencerros. Se coloca frente al anciano y las niñas, entrega las tenazas, se despoja de la máscara y se la entrega al hombre, grita y los otros carochos cruzan el río gritando y desaparecen. Entonces el anciano deja la máscara y las tenazas a las niñas y desaparece por el puente hecho tinieblas gracias a los efectos del humo. Finalmente se canta la canción y se sucede un comensalismo y baile. La fiesta es para todos (Figura 18). 


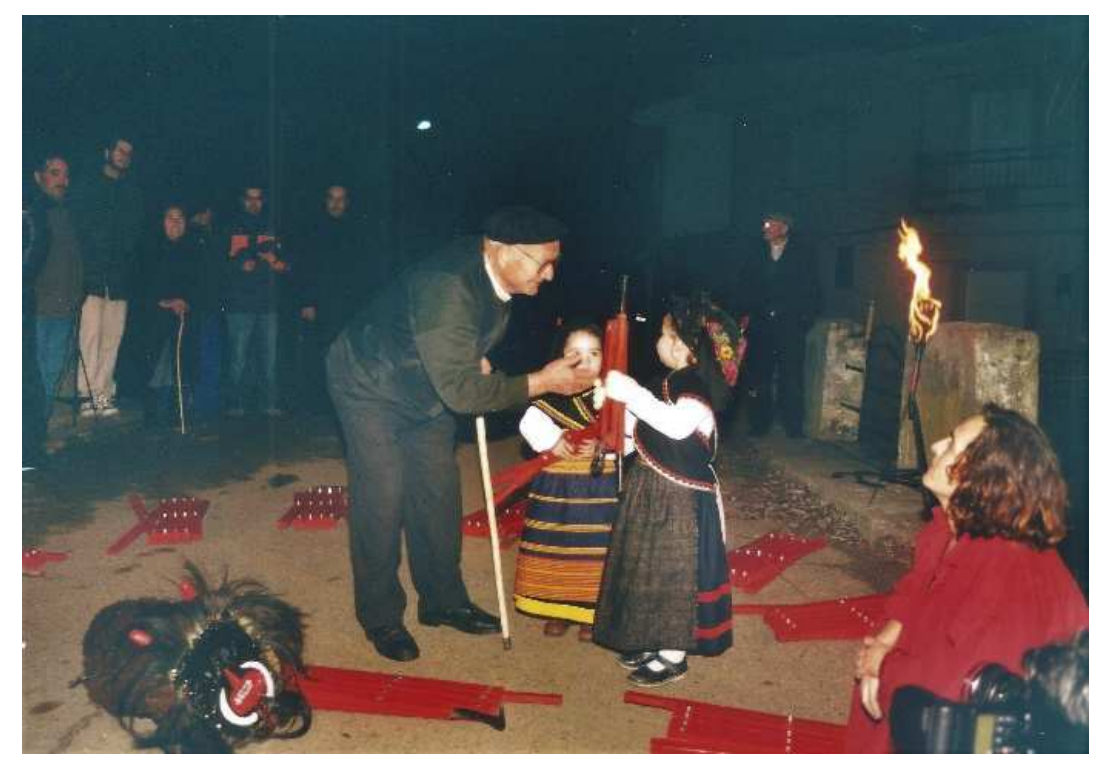

Figura 18. Francisco delante de la carocha depositada en el suelo entrega (tradere) el testigo a las niñas Ainhoa y Almudena antes de desaparecer. La ley de vida se cumple y la rueda de la tradición sigue rodando. Fotografía de Emilio Gallego.

Mediante una teatralización, la mascarada también lo es, se han transmitido los valores de Riofrío a través de informaciones y explicaciones, pero sobre todo con la experiencia y testimonio de los mayores porque la creencia no se aprende con la información, sino con la vivencia:

La transmisión de la cultura es algo que nos hacemos unos a otros, como cuando nos queremos o nos maltratamos. Ese hacernos es una relación de persona a persona. Captar el valor en el testimonio personal de aquellos con quienes se interactúa constituye una aprehensión cualitativamente diferente del aprendizaje curricular basado en la explicación y el estudio (Sanmartín Arce 2007: 471).

\section{CONCLUSIÓN: LA EXPERIENCIA HUMANA SE RECICLA}

La única correspondencia que une la antropología teatral y la antropología cultural es entender que nuestra tradición conocida y obvia puede "revelarse como un nudo de problemas inexplorados" según Eugenio Barba (2005: 27). El ritual ofrece una conducta fija y sancionada por la tradición, aunque siempre se 
esté negociando en función de las circunstancias y de los intereses del grupo ejecutor. Sin embargo, los participantes en principio aceptan el rito como bueno. En cambio, la conducta restaurada como teatro nos ofrece una gran libertad pudiéndose modificar. En la performance estética los sucesos o hechos no se conciben como naturales, sino desde la libertad de la elección individual y colectiva y son siempre susceptibles de ser revisados sin la negociación que sí requiere el rito (Schechner 2011: 37-38).

Alkimia 130 es una compañía que trabajaba con una perspectiva de género y, aunque la mascarada no excluye a la mujer que siempre está en la comunidad y en los preparativos organizando, manteniendo, cosiendo, arreglando..., sí desaparece públicamente del rito que es ejecutado por varones jóvenes incluso en los papeles de La Madama y La Gitana travestida después en La Filandorra. El proceso para adaptar la mojiganga del día 1 de enero a un espectáculo teatral se realizó salvando este escollo. Fue en parte planificado y en parte fruto de la casualidad en lo que para la directora artística fue una suerte de justicia poética (Entrevista a Mercedes Herrero, 13/09/2019). El relevo de la tradición de los viejos a los jóvenes de la comunidad lo iban a poner en escena un hombre mayor llamado Francisco González González, el primero en encarnar a la Carocho Grande de todos los hombres vivos en el momento de La tenazada, y un niño pequeño. Finalmente, el niño no pudo estar y el relevo se le dio a una niña también pequeña que, por timidez, hizo el papel con otra niña, Ainhoa Blanco Yurrebaso y Almudena Antón Blanco. Las mujeres, que para Mercedes Herrero son "buenas compartidoras, comunicadoras" que dan el testimonio debían estar representadas porque “...no es que ellas no estén [en la tradición], es que ellos son complejos en la participación. En todos los lugares y en el mundo rural lo son (Entrevista, 13/09/2019). ${ }^{13}$ Esta participación femenina no supuso ningún inconveniente, y no solo porque riofrienses no sean fervientes defensores de la "pureza" (mímesis); sino porque la comunidad asume que es probable que en algún momento no lejano las jóvenes se incorporen públicamente al rito. Esto sucede ya en la mayoría de las mascaradas de la misma área cultural, la provincia zamorana y el distrito de Bragança (Díaz Lorenzo et alli, 2020), y es una constante en la mayoría de las tradiciones.

La performance de Alkimia 130 como espectáculo no simplifica la complejidad de la mascarada, sino que, al representarse en el espacio del rito con sus ejecutoresmantenedores, los distancia de lo suyo como si fuera algo ajeno. Este desarraigo

${ }^{13}$ Hilando filando en 2009, fue una ocasión para que a través de La Filandorra la mujer tomase la palabra en la recreación del rito. 
ejercita la mirada sobre los valores que encierran Los Carochos, pero sin las veladuras que se dan en otras performances habituales en los últimos años como son los desfiles de enmascarados. Los Carochos han participado en varios (Panero García 2020: 13) que, si bien tienen alguna ventaja importante: el conocimiento y cooperación entre los grupos que participan de la cultura de la máscara en un ambiente lúdico y distendido; y también pueden ser un excelente complemento para comunidades pequeñas que sistemáticamente son excluidas por los distintos gobiernos de atención política y social, por lo que momentáneamente se visibilizan. Sin embargo, estos desfiles tienen una importante desventaja pues utilizan la tradición con una perspectiva exclusivamente teatral que soslaya lo ritual, no fija la memoria local y se homogenizan todas en base a unos pocos elementos, generalmente los más estridentes y grotescos, desinformando más que informando.

Los actores profesionales de La tenazada se ligan con esta performance al público y a los actores locales porque no se exhiben, o no solo. A pesar de lo ficcional los habitantes de Riofrío conciben la teatralidad como una convención cultural reconociéndose en la ficción. Pero la convención cultural está condicionada por los vaivenes de la historia y el rito se recrea en un momento en que está en auge $\mathrm{y}$, sorteando muchas barreras, se ha mantenido hasta el presente. La performance recrea el rito, como apuntamos, pero sobre todo recrea el anhelo comunitario que condensa el fragmento de la canción de Parra: "El rito no nos enseña otra cosa: sobrevivir, si uno lo desea, es comprender que uno no está nunca completamente solo" (Augé 2004: 105). La tradición codificada se aprende, pero no sobrevive si está fosilizada pues necesita ser reformulada continuamente, rebasar los límites que la encorsetan siguiendo el pensamiento de Victor Turner. Los Carochos, y por extensión otras mascaradas como las de fustigadores o tauromaquias grotescas, se componen de distintas categorías que son indisociables - estéticas, económicas, políticas y sociales- que han evolucionado desde el modelo de un sistema autárquico de la "vida simplicísima y morigerada de los campesinos de Aliste" (Méndez Plaza 1902: 23), que se mantuvo hasta la feroz emigración, al modelo global. Recuperamos la respuesta que una informante de Villacidayo (León) le da José Luis Puerto cuando le pregunta por el momento en que desaparecen las veladas vecinales nocturnas: "en el momento en que empezó a prosperar uno" (2009: 102). La contestación es reveladora.

En un territorio en el que la atonía demográfica es una gran tragedia, la supervivencia de las tradiciones solo es viable si estas evolucionan y se adaptan cuantitativamente, pero también cualitativamente. Entre el orden rural antiguo y 
su extinción hay un periodo de inflexión que se da en los años 70 cuando los jóvenes, al socaire de los nuevos tiempos, intervienen recuperando el rito perdido en la década de los años 60. Si la canción citada de Eliseo Parra, que la compañía incorpora como lema y tesis de su recreación, non è vera, è ben trovata.

\section{BIBLIOGRAFÍA}

AA.VV. (2021): Los Carochos, 9.

ABRAHAM, L. E. (2008): Escenas que sostienen mundos. Mímesis y modelos de ficción en el teatro, Madrid, Consejo Superior de Investigaciones Científicas.

ALONSO PONGA, J. L. (2008), Las campanas, León, Edilesa.

AUGÉ, M. (2004): ¿Por qué vivimos?, Barcelona, Gedisa.

BARBA, E. y SAVARESE, N. (1988): Diccionario de antropología teatral, México, Grupo Editorial Gaceta.

BARBA, E. (2005): La canoa de papel: tratado de antropología teatral, Buenos Aires, Catálogos.

BLANCO GONZÁLEZ, J. F. (2004): Los Carochos. Rito y tradición en Aliste, Zamora, Semuret.

BLANCO GONZÁLEZ, J. F. (2009): "Tiempo de máscaras: Los Carochos de Riofrío de Aliste (Zamora)", Argutorio, 12, o. 22, pp. 59-65.

CALVO BRIOSO, B. (2012): Mascaradas de Castilla y León. Tiempo de fiesta. Junta de Castilla y León. Consejería de Cultura y Turismo. Disponible en: http://www.jcyl.es/jcyl/patrimoniocultural/mascaradas/fichas/mascaradas.pdf

CARAMANZANA, J. (director.), TIZA, A. A. PINELO, ALONSO PONGA, J. L., PANERO GARCÍA, M.․ P. (guionistas) (2019): Mascaradas de invierno de la Raya Ibérica en el antiguo territorio Zoela / Winter masquerades of Raya Ibérica in the ancient Zoela territory [Documental (Spanish and Portuguese. English subtitles) para la candidatura Intangible Cultural Heritage Section UNESCO], ZASNET, Asociación Europea de Cooperación (AECT)-Fotografía y Vídeo Carrera, S. L.

CARO BAROJA, J. (1965) (2006): El Carnaval. Análisis histórico-cultural, Madrid, Alianza Editorial.

DELGADO PASCUAL, J. J. (2017): “Entrevista. Mercedes Herrero", Revista informativa de CAS, 4, pp. 4-7. Disponible en: https://docplayer.es/89749602Entre-todocas-mercedes-herrero-perez-soy-mujer-y-si-quiero-vivir-en-elpueblo.html 
DÍAZ LORENZO, M. (coord.), TIZA, A. A. PINELO, ALONSO PONGA, J. L., PANERO GARCÍA, M. P. PÁNCHEZ DOMÍNGUEZ, C. y HERRERO LUQUE, D. (2020): Mascaradas de inverno da Raia Ibérica no antigo território Zoela Mascaradas de invierno de la Raya Ibérica en el antiguo territorio Zoela. Inventário do território ZASNET/ Inventario del Territorio ZASNET [Informe científico-técnico], Bragança, ZASNET. Asociación Europea de Cooperación (AECT). Disponible en: http://www.zasnet-aect.eu/pt-pt/mascaradas-de-invernoda-raia-iberica-no-antigo-territorio-zoela-0

DUEÑAS, A. (2019): Las mascaradas de Aliste [documental], Valladolid, La Esgueva Films.

DULZAR, B. (2019): “Educación, cultura y tradición”, Revista digit@l.1 Portal de Educación de la Junta de Castilla y León, 15 de junio, sp. Disponible en: http://revistas.educa.jcyl.es/revista digital/

GARCÍA CANCLINI, N. (1990): Culturas híbridas. Estrategias para entrar en la modernidad, México, Grijalvo.

GENETTE, G. (1989): Palimpsestos: la literatura en segundo grado, Madrid, Taurus.

GRILLO TORRES, M.a P. (2004): Compendio de teoría teatral, Madrid, Biblioteca Nueva.

HIDALGO BLANCO, L., CHIMENO GONZÁLEZ, B. Y J. M. CANAS MORÁN (2017): "Todos somos carochos", Los Carochos, 5, pp. 4-6.

HERRERO PÉREZ, M. (2013): “ ¿Hicimos teatro contemporáneo?”, Los Carochos, p. 3.

MACHO BLANCO, I. (2018a): “Máscaras en acción: Los Carochos”, Revista digit@l.1 Portal de Educación de la Junta de Castilla y León, 15 de octubre, sp. Disponible en: http://revistas.educa.jcyl.es/revista digital/

MACHO BLANCO, I. (2018b): "Demonios en gris", Revista digit@l.l Portal de Educación de la Junta de Castilla y León, 15 de diciembre, sp. Disponible en: http://revistas.educa.jcyl.es/revista digital/

MÉNDEZ PLAZA, S. (1902): "Cooperación agrícola en tierra de Aliste", en Derecho consuetudinario y Economía popular de España. Tomo 2o. Cap. III. Zamora, Barcelona, Manuel Soler Editor, pp. 23-34. Disponible en: http://bdhrd.bne.es/viewer.vm?id=0000013252\&page $=1$

MÉNDEZ PLAZA, S. (2002): Costumbres comunales de Aliste, introducción de J. I. Plaza Gutiérrez y L. A. Hortelano Mínguez, Zamora, Ayuntamiento de Riofrío de Aliste-Semuret. 
PANERO GARCÍA, M. a P. (2020): "«Que de hoy en un año». La oralidad en una mascarada: Los Carochos de Riofrío de Aliste”, Boletín de Literatura Oral. Antropología, cultura popular y oralidad en los medios digitales, vol. extraordinario 3, pp. 28-58. DOI: 10.17561/blo.vextra3.5252

PRIETO STAMBAUGH, A.; TORIZ PROENZA, M. (2015): "Performance: entre el teatro y la antropología”, Diario de Campo, 6-7, pp. 22-31.

PUERTO, J. L. (2009): Teatro popular, León, Edilesa.

RODRÍGUEZ PASCUAL, F. (2009). Mascaradas de invierno en la provincia de Zamora, Zamora, Semuret.

SANMARTÍN ARCE, R. (2007): "Realidad de los valores en la cultura", en Introducción a la antropología social y cultural. Teoría, método y práctica, editado por C. Lisón Tolosana, Madrid, Akal, pp. 459-477.

SCHECHNER, R. (1988): "Restauración del comportamiento", en Diccionario de antropología teatral, editado por E. Barba y N. Savarese, México, Grupo Editorial Gaceta, pp. 186-194.

SCHECHNER, R. (2011): "Restauración de la Conducta", en Estudios avanzados de performance, editado por D. Taylor y M. Fuentes, México, Fondo de Cultura Económica, pp. 31-49.

TAYLOR, D. (2011): "Introducción. Performance, teoría y práctica", en Estudios avanzados de performance, editado por D. Taylor y M. Fuentes, México, Fondo de Cultura Económica, pp. 7-30.

TIZA, A. A. PINELO (2013): Mascaradas e Pauliteiros. Etnografía e educaçao, Lisboa, Eranos.

TURNER, V. W. (1982): Fron Ritual to Theatre: the human seriousness of play, New York, PAJ Publications.

Recibido: 19 de diciembre de 2020

Aceptado: 14 de enero de 2021 
M.. Pilar Panero García es profesora asociada de Literatura en el Dpto. de Literatura Española y Teoría de la Literatura y Literatura Comparada (Universidad de Valladolid). Desde el año 2005 está vinculada a la Cátedra de Estudios sobre la Tradición de la que es secretaria. Ha sido miembro de los equipos en varios proyectos de investigación, recientemente uno sobre las mascaradas del territorio de La Raya entre Tras-ós-Montes y Zamora y Salamanca. Desde 2009 es investigadora en el proyecto «C. I. de Estudios sobre la Religiosidad Popular: la Semana Santa» y desde 2020 colabora en el proyecto «The Interpretation of Childbirth in Early Modern Spain» (Universität Wien). Sus líneas de investigación son: el Patrimonio Cultural, la Religiosidad Popular y la Literatura desde la Antropología Cultural. Ha participado de la organización de numerosas actividades de carácter científico académico y también de extensión universitaria. mariapilar.panero@uva.es 